\title{
Investigation of the Coupled Effects of Molecular Weight and Charge \\ Transfer Interactions on the Optical and Photochemical Properties of Dissolved Organic Matter
}

\author{
Garrett McKay $^{1 *}$, Kylie D. Couch ${ }^{1,2}$, Stephen P. Mezyk ${ }^{2}$, Fernando L. Rosario-Ortiz ${ }^{1 *}$ \\ ${ }^{1}$ Department of Civil, Environmental, and Architectural Engineering, University of Colorado at \\ Boulder \\ ${ }^{2}$ Department of Chemistry and Biochemistry, California State University Long Beach \\ *Corresponding authors: Garrett McKay (garrett.mckay@colorado.edu) and Fernando Rosario- \\ Ortiz (Fernando.Rosario@colorado.edu)
}

This supporting information section contains a total of 34 pages, with 5 tables and 15 figures.

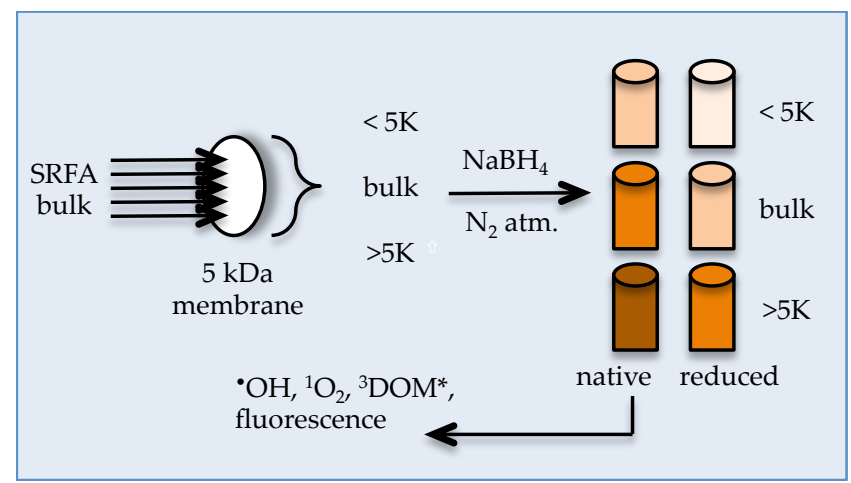




\section{Table of Contents}

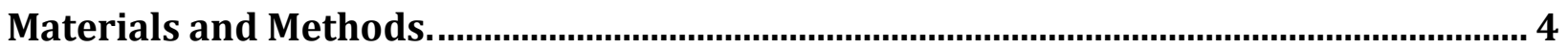

Additional notes about CT states ............................................................................... 7

Calculations on the number of carbonyl groups in SRFA …............................................... 9

Additional discussion of the relationship between RI quantum yields and molecular

weight using current models............................................................................................11

Analysis of whether preferential removal of long wavelength absorption by borohydride reduction increases the apparent quantum yield because of the RI wavelength dependence

Table S1. Water quality of samples undergoing the base-modification and coagulation procedures. .....................................................................................................14

Table S2. Average SEC retention time $\left(\mathrm{R}_{\mathrm{t}}\right)$ for all samples..............................................15

Table S3. Data on various metrics for determining CT contributions to DOM absorbance and fluorescence.

Table S4. Polychromatic quantum yields calculated over different wavelength intervals

Table S5. Results of linear correlations between $\Phi_{102}$ and E2/E3 as measured in this study. Sample acronyms are BC (Boulder Creek), BWW (Boulder Wastewater), OCWD (Orange County Wastewater), LM (Longmont Wastewater), SRFA (Suwanee River Fulvic Acid).

Figure S1. Time course of absorbance spectra $(1 \mathrm{~cm}$ pathlength) for SRFA plotted from 254 to $600 \mathrm{~nm}$ for SRFA $<5 \mathrm{~K}$, unfractionated, and $>5 \mathrm{~K}$ before and after reduction with sodium borohydride over the time period of this study.

Figure S2. (Left) Lamp spectra (black, left axis) for Oriel 94041 A solar simulator described in main text and absorbance spectra (red, right axis) for Boulder Creek non-base-modified. (Right) calculation of the rate of light absorption by DOM based on eq. $S$ 2).

Figure S3. Size exclusion chromatograms for pre-and post-base-modified samples. Solution and eluent conditions are given in ref. ${ }^{28}$ Detector was a VWD set at $254 \mathbf{n m}$.

Figure S4. Size exclusion chromatograms for LM wastewater pre- and postcoagulation with alum. Note that DOC signal in top plot has been baseline subtracted (actual baseline was around $800 \mathrm{mV}$ ). Solution and eluent conditions are given in ref. ${ }^{28}$

Figure S5. Size exclusion chromatograms for for SRFA $<5 \mathrm{~K}$, unfractionated, and $>5 \mathrm{~K}$ before reduction with sodium borohydride. a) DOC response and b) UV response at $254 \mathrm{~nm}$. Solution and eluent conditions are given in ref. ${ }^{28}$ 
Figure S6. Size exclusion chromatograms for SRFA $<5 K$, unfractionated, and $>5 K$ before (solid, black line) and after reduction (dashed, red line) with sodium borohydride. Solution and eluent conditions are given in ref. ${ }^{28}$

Figure S7. (First row) Absorbance spectra (1 cm pathlength) plotted from 254 to 600 nm for BWW, OCWD, and BC. (Second row) Molar absorptivity on a per-carbon basis based on data in first row and TOC values in Table S1. (Third row) Fractional absorbance based on data in first row. nBM and BM refer to non-base-modified and base modified, respectively.

Figure S8. Absorption spectra (1 cm pathlength) for LM wastewater plotted from 254 to $600 \mathrm{~nm}$ and fractional absorbance based on data in a).

Figure S9. Apparent fluorescence quantum yields for LM wastewater as a function of increasing alum dose.

Figure S10. Absorption spectra (1 cm pathlength) plotted from 254 to $600 \mathrm{~nm}$ for SRFA $>$ 5K and SRFA $<$ 5 K fractions pre- and post-reduction. $f_{\mathrm{a}, \min }$ values for SRFA $>5 \mathrm{~K}$ and SRFA $<5 \mathrm{~K}$ are 0.401 and 0.573 , respectively.

Figure S11. Plot of $\varepsilon_{\text {red }}-\varepsilon_{\text {nat }}$ for SRFA molecular weight fractions. Integration of the area between the curve and $\varepsilon_{\text {red }}-\varepsilon_{\text {nat }}=0$ gives the area for the metric provided in Table S3 (row 3).

Figure S12. Plots of apparent $\Phi$ versus E2/E3 for all samples in this study. See legend for sample identity. Solid line for ${ }^{1} \mathrm{O}_{2}$ represents linear regression of $\Phi_{102}$ and E2/E3 excluding SRFA reduced samples. Regression relation is $\Phi_{102}(\%)=1.59 \times E 2 / E 3-$ 5.29. Both the slope $(p<0.0001)$ and intercept $(p<0.01)$ are significant.

Figure S13. Three dimensional excitation emission matrices for BC, BWW, and OCWD pre- and post-base-modification.

Figure S14. Three dimensional excitation emission matrices for $\mathrm{LM}$ as a function of coagulation dose. From top left: Coag0 = $0 \mathrm{mg}$ alum/L, Coag1 = $30 \mathrm{mg}$ alum/L, Coag2 = $60 \mathrm{mg}$ alum $/ \mathrm{L}$, Coag $3=90 \mathrm{mg}$ alum $/ \mathrm{L}$.

Figure S15. Three dimensional excitation emission matrices for SRFA before and after reduction with sodium borohydride. 
1 Materials and Methods.

2 Water Sample Information. Wastewater samples included secondary treated wastewater effluent

3 from Boulder Wastewater Treatment Facility (BWW), which uses UV disinfection prior to

4 effluent release and secondary effluent (pre-chlorination) used by the Orange County Water

5 District (OCWD) as influent to its advanced wastewater recycling facility. The latter sample is a

6 blend of nitrified activated sludge and trickling filter effluents produced by the Orange County

7 Sanitation District. Longmont Wastewater Treatment Facility (LM) samples were secondary

8 treated and disinfected with UV light prior to collection. An additional sample was collected

9 from Boulder Creek (BC) at $75^{\text {th }}$ and Jay St. (Boulder, CO), which is ca. 100 yards downstream

10 of wastewater effluent discharge. This sample was subjected to the same base-modification

11 treatment described in the main text, but no visible precipitate formed. This sample was used as a

12 control for assessing the effect of base modification on DOM when coagulation did not occur.

13 Samples were collected in pre-combusted amber glass bottles, filtered with pre-combusted and

14 rinsed $0.7 \mu \mathrm{m}$ glass fiber filters, and stored at $4{ }^{\circ} \mathrm{C}$. Samples were used over several months.

\begin{tabular}{|l|l|l|l|}
\hline Chemical & Cas no. & Source & Purity \\
\hline $\mathrm{KH}_{2} \mathrm{PO}_{4}$ & $7778-77-0$ & Fischer & $>99.9 \%$ \\
\hline $\mathrm{K}_{2} \mathrm{HPO}_{4}$ & $10028-24-7$ & Fischer & $>99 \%$ \\
\hline Phosphoric acid & $7664-38-2$ & \multicolumn{1}{|c|}{ EMD Millipore } & $85 \%\left(\mathrm{H}_{3} \mathrm{PO}_{4} / \mathrm{H}_{2} \mathrm{O}\right) \mathrm{w} / \mathrm{w}$ \\
\hline Benzene & $71-43-2$ & Alfa Aesar & $99.8 \%$ \\
\hline Phenol & $108-95-2$ & Sigma & $>99 \%$ \\
\hline Furfuryl alcohol & $98-00-0$ & TCI America & $>97 \%$ \\
\hline Trimethyl phenol & $527-60-6$ & Across Organics & $>98.5 \%$ \\
\hline Methanol & $67-56-1$ & BDH & $\mathrm{HPLC}$ grade \\
\hline Amplex red kit & n/a & Life Technologies Corp. & n/a \\
\hline Stop reagent kit & n/a & Life Technologies Corp. & n/a \\
\hline $\mathrm{H}_{2} \mathrm{O}_{2}$ & $7722-84-1$ & BDH & $30 \%\left(\mathrm{H}_{2} \mathrm{O}_{2} /\right.$ water $) \mathrm{w} / \mathrm{w}$ \\
\hline
\end{tabular}


15 Analytical Methods. HPLC. An Agilent 1200 Series HPLC with a variable wavelength detector

16 (VWD) was used to analyze concentrations of probe compounds used in photolysis experiments.

17 Either an Eclipse XBD C-18 or Eclipse Plus C-18 column was used $(1.5 \times 250 \mathrm{~mm}$ dimensions, $185 \mu \mathrm{m}$ particle size).

$19 \underline{{ }^{1} \mathrm{O}_{2}}$ Measurement. Degradation of 2-furanmethanol (furfuryl alcohol, FFA) was used to 20 measure the rate of ${ }^{1} \mathrm{O}_{2}$ production, $R_{102}$, (e.g. see ref ${ }^{1}$ ) at a concentration of ca. $22.5 \mu \mathrm{M}$.

21 Pseudo-first order rate constants for furfuryl alcohol loss allowed for calculation of $R_{1 \mathrm{O} 2}$ using

22 the known rate constant for this reaction as well as the rate constant for physical quenching of

$23{ }^{1} \mathrm{O}_{2}$ by water. HPLC detection was accomplished using VWD at $219 \mathrm{~nm}$ and a gradient of $\mathrm{pH}$

242.3 phosphoric acid (ca. $10 \mathrm{mM}$ ) and methanol: $30 / 70$ ramped to $50 / 50$ from 0 to 5 minutes.

25 Furfuryl alcohol eluted at $3.2 \pm 0.2$ minutes under these conditions. Measured concentrations

26 were far above the detection limit for furfuryl alcohol.

$27 \quad{ }^{3} \mathrm{DOM}^{*}$ Estimation. ${ }^{3} \mathrm{DOM}^{*}$ quantum efficiencies were estimated using the electron 28 transfer probe 2,4,6-trimethylphenol (TMP). This method has been explained in detail 29 previously. ${ }^{2}$ Briefly, because DOM has a spectrum of triplet states, all of which react at different 30 rate constants with TMP, exact quantification of ${ }^{3} \mathrm{DOM}^{*}$ formation rates are not attainable.

31 However, the pseudo-first order rate for TMP loss can be used (at a fixed TMP concentration) to 32 calculate the quantum efficiency for TMP loss, $f_{\mathrm{TMP}}\left(\mathrm{M}^{-1}\right)$, which is proportional to the quantum 33 yield for ${ }^{3} \mathrm{DOM}^{*}{ }^{2}$. This analysis works under the assumption that both $k_{\mathrm{TMP}}$ and $\Sigma k_{3 \mathrm{DOM}^{*}}$ are 34 constant, which represent the second order rate constant between ${ }^{3} \mathrm{DOM}^{*}$ and TMP and the sum 35 over all first- and pseudo-first order ${ }^{3} \mathrm{DOM}^{*}$ loss reactions, respectively. In this study, a TMP 36 concentration of $5 \mu \mathrm{M}$ was used. HPLC measurement of TMP loss was accomplished using 37 VWD at $219 \mathrm{~nm}$ and an isocratic flow of $\mathrm{pH} 2.3$ phosphoric acid and methanol (40/60). TMP 
38 eluted at $7.0 \pm 0.2$ minutes under these conditions. Measured concentrations were far above the 39 detection limit for TMP.

$40 \quad \mathrm{OH}$ Measurement. ${ }^{\circ} \mathrm{OH}$ was measured by following the formation of phenol from the 41 oxidation of benzene $(3 \mathrm{mM})$. The previously determined yield of 0.63 from this reaction was 42 used to convert the rate of phenol formation into the rate of ${ }^{\circ} \mathrm{OH}$ formation. ${ }^{3}$ While not all of the 43 phenol produced is formed from free ${ }^{\circ} \mathrm{OH}$, all reported values used this conversion for 44 consistency with previous studies. ${ }^{3}$

45 For whole water samples, nitrate and nitrite concentrations (Talble S1) were used to 46 calculate the formation rate of ${ }^{\circ} \mathrm{OH}$ from these species by using a calibration curve, similar to the 47 procedure of Dong and Rosario-Ortiz. ${ }^{4}$ The remaining ${ }^{\circ} \mathrm{OH}$ formation rate was then attributed to 48 DOM photolysis. Phenol was detected using HPLC with VWD detection at $210 \mathrm{~nm}$. An isocratic 49 mobile phase of $60 \% \mathrm{pH} 2.3$ phosphoric acid (ca. $10 \mathrm{mM}$ ) $40 \%$ methanol was used. Under these 50 conditions, phenol eluted at $4.8 \pm 0.2$ minutes. The limit of detection under these conditions (for 51 phenol in deionized water) was around $20 \mathrm{nM}$ while the limit of quantitation was around $55 \mathrm{nM}$.

52 These limits were slightly greater in DOM-containing solutions due to background DOM 53 absorbance.

54 Estimation of polychromatic quantum yields. The quantum yield for ROS production can be 55 defined as the rate of that process divided by the rate of light absorption

$$
\Phi=\frac{R_{R O S}}{R_{a-D O M}}
$$

$57 R_{\mathrm{ROS}}\left(\mathrm{M} \mathrm{s}^{-1}\right)$ is measured as described above, while the rate of light absorption by DOM, $R_{\mathrm{a}-\mathrm{DOM}}$

$58\left(\mathrm{Es} \mathrm{L}^{-1} \mathrm{~s}^{-1}\right)$, is calculated. $f_{\mathrm{TMP}}$ is calculated by dividing the measured pseudo first order rate 59 constant for TMP loss (at $[\mathrm{TMP}]_{0}=5 \mu \mathrm{M}$ ) by $R_{\mathrm{a}-\mathrm{DOM}}$. For the polychromatic system used here, 
$R_{\mathrm{a}-\mathrm{DOM}}$ is equal to the specific rate of light absorption, which is a sum over all wavelengths of

61 interest, ${ }^{5}$ times the DOM concentration:

62

$$
\begin{aligned}
R_{a-D O M} & =k_{a-D O M}[\mathrm{DOM}]= \\
& =\sum_{\lambda=290}^{i} \frac{E_{p, \lambda}^{0} \varepsilon_{\lambda}\left(1-10^{-\varepsilon_{\lambda}[\mathrm{DOM}] z}\right)}{\varepsilon_{\lambda}[\mathrm{DOM}] z}[\mathrm{DOM}]= \\
& =\sum_{\lambda=290}^{i} \frac{E_{p, \lambda}^{0}\left(1-10^{-A_{\lambda} z}\right)}{A_{\lambda} z} A_{\lambda}= \\
& =\sum_{\lambda=290}^{i} \frac{E_{p, \lambda}^{0}\left(1-10^{-A_{\lambda} z}\right)}{z} .
\end{aligned}
$$

63 with the terms above defined as: $k_{\mathrm{a}-\mathrm{DOM}}$ (specific rate of light absorption), [DOM] (concentration

64 of carbon in molar), $E_{p, \lambda}^{0}$ (spectral photon flux at wavelength $\lambda$ ), $\varepsilon_{\lambda}$ (molar absorptivity of DOM

65 at wavelength $\lambda$ defined on a molar carbon basis), $z$ (optical pathlength). In eq. S2, wavelengths

66 are summed between $290 \mathrm{~nm}$ and $i$ where $i$ represents the upper wavelength limit. This is

67 represented in Figure S2 in which the lamp spectra, DOM absorbance spectra, and wavelength

68 dependent rate of light absorption by the system are shown. The AM 1.5 filter as shown cuts off

69 wavelengths below ca. $290 \mathrm{~nm}$ and $i$ was typically equal to $400 \mathrm{~nm}$. Table $\mathrm{S} 4$ shows results for

70 calculations of quantum yields for fluorescence, ${ }^{1} \mathrm{O}_{2},{ }^{\circ} \mathrm{OH}$, and ${ }^{3} \mathrm{DOM}^{*}$ in which the upper bound

71 was varied (see Analysis of whether preferential removal of long wavelength absorption by

72 borohydride reduction increases the apparent quantum yield because of the RI wavelength

73 dependence section below).

75 Additional notes about CT states

76 The CT model attributes much of DOM photophysics to intramolecular CT interactions. For

77 DOM, these states arise from either partial or complete transfer of an electron between electron-

78 rich donors (hydroxy-/alkoxy-benzenes) and electron-poor acceptors (carbonyl-containing 
79 moieties like quinones or aromatic ketones). These groups can be denoted as D and A,

80 respectively, and a CT state is typically written as ${ }^{1}\left(\mathrm{D}^{+} / \mathrm{A}^{-}\right)$indicating transfer of an electron

81 from $\mathrm{D}$ to $\mathrm{A}$. The superscript is meant to indicate that the excited state is a singlet state.

82 Parentheses around D and A are meant to indicate the close association between D and A groups

83 within a DOM molecule. This can also be denoted as $\mathrm{DOM}^{+/ \bullet^{-}}$, which similarly describes

84 transfer of an electron, although it is implicit here that the transfer is from a D to an A group.

$85^{1}\left(D^{*}+A\right)$ indicates a local singlet excited donor, ${ }^{1}\left(D+A^{*}\right)$ indicates a local singlet excited 86 acceptor, and ${ }^{3}\left(\mathrm{D}+\mathrm{A}^{*}\right)$ indicates a local triplet excited acceptor.

87 In principle, these interactions are possible in either the ground or excited electronic state.

88 Weak CT complexes have little to no CT character in the ground state, but significant CT

89 character in an electronic excited state. ${ }^{6}$ Here, character is specified by the contribution of the

90 dative-bond (in which complete electron transfer has occurred) wave function $\left(\psi_{1}\right)$ to the ground

91 state. For a given DA complex, the ground-state wave function can be written as (eq. S3) $)^{6,7}$

$92 \quad \psi_{N}(D, A)=a \psi_{0}(D / A)+b \psi_{1}\left(D^{+} / A^{-}\right)$

93 and the excited state wave function can be written as (eq. S4)

$94 \quad \psi_{E}(D, A)=a^{*} \psi_{1}\left(D^{+} / A^{-}\right)+b^{*} \psi_{0}(D / A)$

95 The coefficients $a, b, a^{*}, b^{*}$ describe the contribution of each state (no bond $\left(\psi_{0}\right)$ and dative96 bond) to the total wave function of the ground and excited state, respectively. For weak CT

97 complexes, $a \simeq a^{*} \simeq 1$ and $b \simeq b^{*} \simeq 0$. These coefficients have yet to be characterized for DOM

98 and thus it is presently unknown if the CT interactions within DOM are primarily in the ground

99 or an electronic excited state. Future research should explore this question.

100 Formation of a CT state could occur either by excited state electron transfer (eqs. S3, S4) 


$$
{ }^{1}(D+A)+h v \rightarrow{ }^{1}\left(D^{*}+A\right)
$$

$$
{ }^{1}\left(\mathrm{D}^{*}+\mathrm{A}\right) \rightarrow{ }^{1}\left(\mathrm{D}^{+} / \mathrm{A}^{-}\right)
$$

or by direct excitation into a CT state (eq. S5)

$$
{ }^{1}(\mathrm{D}+\mathrm{A})+\mathrm{hv} \rightarrow{ }^{1}\left(\mathrm{D}^{+} / \mathrm{A}^{-}\right)
$$

It is important to note that only excitation of a $\mathrm{D}$ group [i.e. to form ${ }^{1}\left(\mathrm{D}^{*}+\mathrm{A}\right)$ ] could lead to a CT state because by definition an excited local acceptor would not donate electron density.

\section{Calculations on the number of carbonyl groups in SRFA}

Below we present an analysis of the statistical likelihood of intramolecular CT interactions for SRFA based on known physicochemical data for this isolate. Discussion is presented first and then the calculations are presented afterwards. Based on the (number average) molecular weight of SRFA (829 Da by vapor pressure osmometry) ${ }^{8}$ and reported carbonyl content (by ${ }^{13} \mathrm{C}-\mathrm{NMR}$, including shifts between 165 to $220 \mathrm{ppm}),{ }^{9}$ the number of carbonyl groups in a SRFA molecule are estimated to be: 2 (aldehyde, ketone) and 7 (ester, carboxylic acid). Using the reported carboxylic acid content of SRFA $\left(6 \mathrm{mmol} \mathrm{g} \mathrm{DOM}^{-1}\right),{ }^{10}$ there are ca. 5 carboxylic acid groups, which leaves ca. 2 ester groups. The CT model states that A groups are primarily aromatic ketones/aldehydes and quinones. ${ }^{11}$ While esters and acids would not be as electron-deficient acceptors as ketones or aldehydes, it seems unlikely that the substantial intramolecular CT interactions attributed to this sample would be configurationally or statistically possible with only 2 A groups per molecule. Based on the below calculations, 4 to 5 A groups per SRFA molecule is a reasonable upper limit for this sample. This estimate assumes that not all of the ester and acid carbonyls act as acceptors. Lower molecular weight DOM likely has fewer than 4 A groups. In fact, two recent reports indicate that terrigeneous humic substances have greater antioxidant and electron donating capacities than aquatic humic substances, ${ }^{2,3,12,13}$ suggesting a 
125 greater proportion of D and A groups within the higher molecular weight (terrigenous) humic 126 material.

127 Detailed calculations are made on the number of carbonyl groups present in SRFA. 128 Relevant carbonyl-containing functional groups in SRFA are aldehydes, ketones, esters, and 129 carboxylic acids. Data for these calculations are derived from the International Humic 130 Substances Society (IHSS) website $\left({ }^{13} \mathrm{C}-\mathrm{NMR}\right.$ estimations of C-content), ${ }^{9}$ Aiken and Malcolm 131 (1987) for the molecular weight of SRFA, ${ }^{8}$ and Thurman and Malcolm (1983) for the carboxylic 132 acid content of SRFA. ${ }^{10}$ Reported estimates of carbon distribution in SRFA (1S101F) obtained 133 from the IHSS website are (chemical shift range, mass \% of total C mass): carbonyl (220-190 $134 \mathrm{ppm}, 7 \%)$ and ester (190-165 ppm, 20\%). The reported molecular weight of SRFA by vapor 135 pressure osmometry is $829 \mathrm{Da}$ and the reported carboxylic acid content is $6 \mathrm{mmol} \mathrm{g} \mathrm{DOM}^{-1}$. The reported \% C by mass for SRFA is $52.44 \% .^{14}$

The number of carbonyl groups from aldehydes and ketones is calculated as

$$
\begin{gathered}
\frac{7 g C=O \text { carbon }}{100 \mathrm{~g} \text { carbon }} \times \frac{0.5244 \mathrm{~g} \text { carbon }}{1 \mathrm{gSRFA}} \times \frac{1 \mathrm{~mol} \text { carbon }}{12 \mathrm{~g} \text { carbon }} \times \frac{1 \mathrm{~mol} \mathrm{C}=\mathrm{O}}{1 \mathrm{~mol} C=O \text { carbon }} \times \frac{829 \mathrm{~g}}{1 \mathrm{~mol} \mathrm{SRFA}} \\
=\mathbf{2} .54 \text { groups per molecule of DOM from aldehydes } / \text { ketones }
\end{gathered}
$$

138 The number of carbonyl groups from esters and carboxylic acids is calculated as

$$
\begin{aligned}
& \frac{20 \mathrm{~g} C=O \text { carbon }}{100 \mathrm{~g} \text { carbon }} \times \frac{0.5244 \mathrm{~g} \text { carbon }}{1 \mathrm{gSRFA}} \times \frac{1 \text { mol carbon }}{12 \mathrm{~g} \text { carbon }} \times \frac{1 \mathrm{~mol} \mathrm{COO}}{1 \text { mol COO carbon }} \\
& \times \frac{829 \mathrm{~g}}{1 \text { mol } S R F A}=7.25 \text { groups } \text { per molecule of DOM from esters } / \text { acids }
\end{aligned}
$$

139 The number of carboxylic acid groups is calculated as

$$
\begin{aligned}
\frac{6 \mathrm{mmol} \mathrm{COOH}}{\mathrm{gSRFA}} & \times \frac{829 \mathrm{~g}}{\mathrm{~mol} \mathrm{SRFA}} \times \frac{1 \mathrm{~mol}}{1000 \mathrm{mmol}}=4.97 \mathrm{COOH} \text { groups } \\
& =\mathbf{4 . 9 7} \text { groups per molecule of DOM from carboxylic acids }
\end{aligned}
$$


140 Thus, the number of carbonyl groups from esters is $7.25-4.97=2.28 \approx 2$.

145 yields and molecular weight than presented in the main text.

146 Increases for $\Phi_{1 \mathrm{O} 2}$ with decreasing molecular weight are attributable to either (i) a greater

147 bulk ${ }^{1} \mathrm{O}_{2}$ steady state concentration with decreasing molecular weight ${ }^{1,15}$ and/or (ii) a greater

148 concentration of or more reactive ${ }^{1} \mathrm{O}_{2}$ precursors. Latch and McNeill (2006) reported greater

$149{ }^{1}\left[\mathrm{O}_{2}\right]_{\mathrm{ss}}$ in the DOM microenvironment as opposed to bulk, aqueous $\left[{ }^{1} \mathrm{O}_{2}\right]_{\mathrm{ss}}$ due to decreased

150 quenching by water in the hydrophobic DOM core. ${ }^{15}$ Thus, for lower molecular weight DOM,

$151{ }^{1} \mathrm{O}_{2}$ would have less distance to diffuse before reaching the aqueous phase, resulting in greater

152 aqueous $\left[{ }^{1} \mathrm{O}_{2}\right]_{\text {ss. }}$ Secondly, the CT model says that DOM excited states can be deactivated to CT

153 states; for example, ${ }^{3} \mathrm{DOM}^{*} \rightarrow \mathrm{DOM}^{+\bullet / \bullet}$. Lower molecular weight DOM would have a decreased

154 rate of such a deactivation pathway and $\Phi_{1 \mathrm{O} 2}$ and $f_{\mathrm{TMP}}$ would increase. The rate of ${ }^{1} \mathrm{DOM}^{*}$

155 deactivation to $\mathrm{DOM}^{+\bullet / \bullet}$ would decrease as well, explaining the concomitant increase in $\Phi_{\mathrm{f}}$.

156 Finally, Figure 4 (main text) also demonstrates an increase in $\Phi_{\mathrm{OH}}$ with decreasing

157 molecular size, which has previously been observed for size-fractionated EfOM obtained by

158 ultrafiltration. ${ }^{16,17}$ The explanation for this is not simple. Although the same correlation is

159 observed for $f_{\mathrm{TMP}}$, it is unlikely that ${ }^{3} \mathrm{DOM}^{*}$ are precursors to free ${ }^{\circ} \mathrm{OH}$. However, ${ }^{3} \mathrm{DOM}^{*}$ could

160 be precursors to low energy hydroxylators. For example, benzene is oxidized to phenol upon

161 irradiation of $p$-benzoquinone, ${ }^{3}$ which likely occurs through a quinone-water exciplex ${ }^{18}$ that

162 results from triplet state $p$-benzoquinone. Figure 5 (main text) as well as Lee et al. (2013) reports

163 a positive correlation between $\Phi_{\mathrm{f}}$ and $\Phi_{\mathrm{OH}}$, which suggests a greater population of excited state 
$164{ }^{\circ} \mathrm{OH}$ precursors. The correlation holds for both DOM undergoing size-fractionation and chemical

165 reduction (SRFA) as well as coagulation (LM wastewater).

166

167 Possible assignments of peak in SEC chromatograms at retention time of $\sim \mathbf{4 5} \mathbf{~ m i n}$

168 The peak observed at a retention time of $\sim 45 \mathrm{~min}$. in the borohydride reduced samples was also

169 observed by Tinnacher and Honeyman (2007), ${ }^{19}$ who labeled the DOM with tritiated $\mathrm{NaBH}_{4}$. In

170 addition to TOC analysis, the Tinnacher and Honeyman study also measured tritium $\left({ }^{3} \mathrm{H}\right)$ activity

171 after elution from the SEC column. This revealed that the DOM responsible for this peak was

172 tritiated. Based on the consistent retention times between native and reduced samples, we feel

173 that the overall effects of this new peak are minimal. However, based on the data of Tinnacher

174 and Honeyman, it does seem likely that lower molecular weight compounds are being produced

175 due to reduction of esters by borohydride.

176 For example, if an ester reacts with tritiated $\mathrm{NaBH}_{4}$, the following reaction occurs

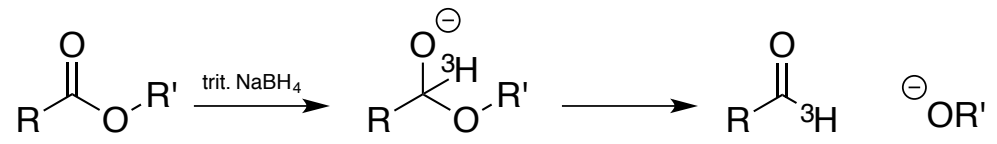

178 The tritiated aldehyde could be further reduced. Either of these products would account for the

179 tritium signal detected by Tinnacher and Honeyman at longer SEC retention times. Based on the

180 fact that the signal at this retention time exhibited tritium activity, it seems unlikely that it is due

181 to ester hydrolysis. Tritiated $\mathrm{NaBH}_{4}$ would not produce a significant amount of $\mathrm{O}^{3} \mathrm{H}^{-}$(see

182 calculations in SI of ref. ${ }^{20}$ ) and so its incorporation into DOM is also expected to be minimal. 
184 Analysis of whether preferential removal of long wavelength absorption by borohydride 185 reduction increases the apparent quantum yield because of the RI wavelength dependence

186 To answer this question, consider that $\Phi$ for RI formation are wavelength dependent (e.g. ref. ${ }^{11}$ ).

187 In a polychromatic system, the rate of light absorption by DOM over all wavelengths of interest, $188 \quad R_{\text {a-DOM, is (eq. S6) }}$

$$
R_{\mathrm{a}-\mathrm{DOM}}=2.303 \int_{\mathrm{all} \lambda} I_{\mathrm{a}}(\lambda) A(\lambda) d \lambda
$$

190

191 accentuated by increasing the upper wavelength bound. S7)

where $I_{\mathrm{a}}$ is the rate of light absorption by the system and $A$ is the solution absorbance in a $1 \mathrm{~cm}$ pathlength, both at wavelength $\lambda$. With these parameters known, the rate of RI formation is (eq.

$$
R_{\mathrm{ROS}}=\int_{\text {all } \lambda} I_{\mathrm{a}-\mathrm{DOM}}(\lambda) \Phi(\lambda) d \lambda
$$

where $I_{\mathrm{a}-\mathrm{DOM}}$ is the rate of light absorption by DOM at wavelength $\lambda$. For ${ }^{1} \mathrm{O}_{2}, \Phi$ is an exponential function of $\lambda .^{11}$ The dependence for ${ }^{\circ} \mathrm{OH}$ is similar. ${ }^{21-23}$ Regardless, $\Phi(\lambda)$ decays to zero quickly past $\sim 350 \mathrm{~nm}$ and thus a substantial portion of the light being absorbed may not be inducing formation of RI, decreasing the calculated value of $\Phi$. To examine this, $\Phi$ values were calculated using the discrete version of eq. S6 $\Phi$ (i.e. eq. S2) with the upper bound of the sum as 350, 400, and $450 \mathrm{~nm}$; results are shown in Table S3. For ${ }^{1} \mathrm{O}_{2}$ and ${ }^{3} \mathrm{DOM}^{*}$, the difference between native and reduced SRFA diminishes as the upper wavelength bound increases. Interestingly, the difference is less pronounced for $f_{\mathrm{TMP}}$ than $\Phi_{1 \mathrm{O} 2}$. Conclusions presented in the main text regarding "environmental" ${ }^{1} \mathrm{O}_{2}$ and ${ }^{3} \mathrm{DOM}^{*}$ quantum yields should be investigated more thoroughly given the above analysis; however, there is good precedent in the literature for choosing an upper wavelength bound of $400 \mathrm{~nm} \cdot{ }^{1,4,16,17,24-26}$ The differences in $\Phi_{\mathrm{OH}}$ are actually 
Table S1. Water quality of samples undergoing the base-modification and coagulation procedures.

\begin{tabular}{|c|c|c|c|c|c|c|}
\hline Sample & $\begin{array}{c}\text { Total Iron (mg Fe/L for } \\
\text { liquids and ppm on } \\
\text { mass basis for solids) }\end{array}$ & $\begin{array}{c}\text { Total } \\
\text { Aluminum }(\mathrm{mg} \\
\mathrm{Al} / \mathrm{L})\end{array}$ & $\mathrm{DOC}(\mathrm{mgC} / \mathrm{L})$ & $\begin{array}{c}\text { Nitrate } \\
(\mathrm{mM})\end{array}$ & $\begin{array}{l}\text { Nitrite } \\
(\mathrm{mM})\end{array}$ & $\operatorname{Abs}(254 \mathrm{~nm})$ \\
\hline $\mathrm{BCnBM}$ & 0.054 & n.m. ${ }^{b}$ & 3.982 & 0.457 & $\mathrm{BDL}^{\mathrm{a}}$ & 0.126 \\
\hline $\mathrm{BCBM}$ & 0.045 & n.m. ${ }^{b}$ & 3.871 & 0.483 & $\mathrm{BDL}^{\mathrm{a}}$ & 0.127 \\
\hline BWWnBM & 0.017 & n.m. ${ }^{b}$ & 5.924 & 0.723 & $\mathrm{BDL}^{\mathrm{a}}$ & 0.112 \\
\hline BWWBM & $\mathrm{BDL}^{\mathrm{a}}$ & n.m. ${ }^{b}$ & 5.144 & 0.723 & $\mathrm{BDL}^{\mathrm{a}}$ & 0.093 \\
\hline BWW ppt & 931 & n.m. ${ }^{b}$ & n.m. ${ }^{b}$ & n.m. ${ }^{b}$ & n.m. ${ }^{b}$ & n.m. $^{\mathrm{b}}$ \\
\hline OCWDnBM & 0.070 & n.m. ${ }^{b}$ & 8.412 & 0.755 & 0.050 & 0.182 \\
\hline OCWDBM & $\mathrm{BDL}^{\mathrm{a}}$ & n.m. ${ }^{b}$ & 7.588 & 0.770 & 0.050 & 0.145 \\
\hline OCWD ppt & 353 & n.m. ${ }^{b}$ & n.m. ${ }^{b}$ & n.m. ${ }^{b}$ & n.m. ${ }^{\text {b }}$ & n.m. ${ }^{b}$ \\
\hline LMCoag 0ppm Alum & 0.060 & $\mathrm{BDL}^{\mathrm{a}}$ & 8.210 & 0.968 & $\mathrm{BDL}^{\mathrm{a}}$ & 0.163 \\
\hline LMCoag 30ppm Alum & 0.034 & 0.028 & 7.200 & 0.945 & $\mathrm{BDL}^{\mathrm{a}}$ & 0.137 \\
\hline LMCoag 60ppm Alum & 0.032 & 0.018 & 6.530 & 1.004 & $\mathrm{BDL}^{\mathrm{a}}$ & 0.118 \\
\hline LMCoag 90ppm Alum & 0.027 & 0.006 & 6.090 & 0.931 & $\mathrm{BDL}^{\mathrm{a}}$ & 0.108 \\
\hline LMCoag 120ppm Alum & 0.024 & 0.017 & 5.470 & 0.932 & $\mathrm{BDL}^{\mathrm{a}}$ & 0.098 \\
\hline
\end{tabular}

${ }^{a}$ below detection limit, ${ }^{b}$ not measured 
Table S2. Average SEC retention time $\left(\mathrm{R}_{\mathrm{t}}\right)$ for all samples.

\begin{tabular}{|l|l|l|l|l|l|}
\hline Sample & $\begin{array}{l}\text { Average } \\
\mathrm{R}_{\mathrm{t}}(\mathrm{min})\end{array}$ & Sample & $\begin{array}{l}\text { Average } \\
\mathrm{R}_{\mathrm{t}}(\mathrm{min})\end{array}$ & Sample & $\begin{array}{l}\text { Average } \\
\mathrm{R}_{\mathrm{t}}(\mathrm{min})\end{array}$ \\
\hline BWW nBM & 13.80 & LM 0 mg Alum/L & 38.13 & SRFA $<$ 5K nat & 31.04 \\
\hline BWW BM & 13.67 & LM 30 mg Alum/L & 37.98 & SRFA $<5$ K red & 31.40 \\
\hline OCWD nBM & 13.61 & LM 120 mgAlum/L & 37.81 & SRFA nat & 29.90 \\
\hline OCWD BM & 13.77 & - & - & SRFA red & 29.98 \\
\hline BC BM & 11.81 & - & - & SRFA $>$ 5K nat & 29.56 \\
\hline BC nBM & 12.03 & - & - & SRFA $>5$ K red & 30.27 \\
\hline
\end{tabular}

Table S3. Data on various metrics for determining CT contributions to DOM absorbance and fluorescence.

\begin{tabular}{|c|c|c|c|c|}
\hline METRIC/SAMPLE & SRFA $<5 \mathrm{~K}$ & $\begin{array}{l}\text { SRFA } \\
\text { bulk }\end{array}$ & SRFA $>5 \mathrm{~K}$ & Similar to $f_{\mathrm{a}, \min }$ result? \\
\hline \multicolumn{5}{|c|}{ Absorbance } \\
\hline$f_{\mathrm{a}, \min }$ & 0.620 & 0.485 & 0.364 & - \\
\hline $\begin{array}{l}\text { Area under } \varepsilon_{\text {red }} / \varepsilon_{\text {nat }} \\
(254 \mathrm{~nm}<\lambda<480 \mathrm{~nm})\end{array}$ & 178 & 132 & 104 & Yes, more area indicates less removal \\
\hline $\begin{array}{l}\text { Area under } \varepsilon_{\text {red }}-\varepsilon_{\text {nat }} \\
(254 \mathrm{~nm}<\lambda<480 \mathrm{~nm})\end{array}$ & -1731 & -11674 & -19949 & $\begin{array}{c}\text { Yes, more negative value corresponds to more } \\
\text { removal }\end{array}$ \\
\hline \multicolumn{5}{|c|}{ Fluorescence } \\
\hline$\left(\Phi_{\mathrm{f}, \text { red }}-\Phi_{\mathrm{f}, \text { nat }}\right) / \Phi_{\mathrm{f}, \text { nat }}$ & 0.82 & 1.15 & 1.25 & - \\
\hline$\left(\Phi_{\mathrm{f}, \text { red }}-\Phi_{\mathrm{f}, \text { nat }}\right)$ & 0.0145 & 0.0109 & 0.00890 & - \\
\hline
\end{tabular}


Table S4. Polychromatic quantum yields calculated over different wavelength intervals

\begin{tabular}{|c|c|c|c|c|c|c|c|c|c|}
\hline \multirow[b]{2}{*}{$290 \leq \lambda \leq 350 \mathrm{~nm}$} & \multicolumn{2}{|c|}{${ }^{1} \mathrm{O}_{2} \mathrm{QY}$} & \multirow[b]{2}{*}{ (Red-Nat)/Red } & \multicolumn{2}{|c|}{${ }^{\circ} \mathrm{OH}$ QY } & \multirow[b]{2}{*}{ (Red-Nat)/Red } & \multicolumn{2}{|c|}{$f_{\mathrm{TMP}}\left(\mathrm{M}^{-1}\right)$} & \multirow[b]{2}{*}{ (Red-Nat)/Red } \\
\hline & Mean & $2 s$ & & Mean & $2 s$ & & Mean & $2 s$ & \\
\hline SRFA $<5 \mathrm{~K}$ nat & $2.77 \mathrm{E}-01$ & $4.13 \mathrm{E}-02$ & & $1.59 \mathrm{E}-04$ & $4.60 \mathrm{E}-05$ & & $3.73 \mathrm{E}+02$ & $4.26 \mathrm{E}+01$ & \\
\hline SRFA $<5 \mathrm{~K}$ red & $2.00 \mathrm{E}-01$ & $3.32 \mathrm{E}-03$ & $-28 \%$ & $2.22 \mathrm{E}-04$ & $5.81 \mathrm{E}-05$ & $40 \%$ & $2.32 \mathrm{E}+02$ & $1.62 \mathrm{E}+00$ & $-38 \%$ \\
\hline SRFA nat & $1.90 \mathrm{E}-01$ & $5.43 \mathrm{E}-03$ & & $1.86 \mathrm{E}-04$ & 7.76E-06 & & $2.64 \mathrm{E}+02$ & $6.88 \mathrm{E}+00$ & \\
\hline SRFA red & $1.41 \mathrm{E}-01$ & $1.28 \mathrm{E}-03$ & $-26 \%$ & $1.74 \mathrm{E}-04$ & $3.72 \mathrm{E}-05$ & $-7 \%$ & $2.11 \mathrm{E}+02$ & $1.03 \mathrm{E}+01$ & $-20 \%$ \\
\hline SRFA $>5 \mathrm{~K}$ nat & $1.65 \mathrm{E}-01$ & $1.05 \mathrm{E}-02$ & & $1.18 \mathrm{E}-04$ & 4.03E-05 & & $2.27 \mathrm{E}+02$ & $2.62 \mathrm{E}+01$ & \\
\hline SRFA $>5 \mathrm{~K}$ red & $1.33 \mathrm{E}-01$ & $9.71 \mathrm{E}-03$ & $-19 \%$ & $1.68 \mathrm{E}-04$ & $3.96 \mathrm{E}-05$ & $43 \%$ & $1.47 \mathrm{E}+02$ & $1.41 \mathrm{E}+01$ & $-35 \%$ \\
\hline $290 \leq \lambda \leq 400 \mathrm{~nm}$ & Mean & $2 s$ & & Mean & $2 s$ & & Mean & $2 s$ & \\
\hline SRFA $<5 \mathrm{~K}$ nat & $3.52 \mathrm{E}-02$ & $5.26 \mathrm{E}-03$ & & $2.03 \mathrm{E}-05$ & $5.86 \mathrm{E}-06$ & & $4.82 \mathrm{E}+01$ & $5.50 \mathrm{E}+00$ & \\
\hline SRFA $<5 \mathrm{~K}$ red & $3.03 \mathrm{E}-02$ & $5.04 \mathrm{E}-04$ & $-14 \%$ & $3.38 \mathrm{E}-05$ & $8.82 \mathrm{E}-06$ & $67 \%$ & $3.56 \mathrm{E}+01$ & 2.49E-01 & $-26 \%$ \\
\hline SRFA nat & $2.13 \mathrm{E}-02$ & $6.10 \mathrm{E}-04$ & & $2.09 \mathrm{E}-05$ & $8.71 \mathrm{E}-07$ & & $3.03 \mathrm{E}+01$ & $1.43 \mathrm{E}+00$ & \\
\hline SRFA red & $1.94 \mathrm{E}-02$ & $1.76 \mathrm{E}-04$ & $-9 \%$ & $2.38 \mathrm{E}-05$ & $5.11 \mathrm{E}-06$ & $14 \%$ & $2.96 \mathrm{E}+01$ & $8.59 \mathrm{E}-01$ & $-2 \%$ \\
\hline SRFA $>5 \mathrm{~K}$ nat & $1.80 \mathrm{E}-02$ & $1.15 \mathrm{E}-03$ & & $1.28 \mathrm{E}-05$ & $4.39 \mathrm{E}-06$ & & $2.52 \mathrm{E}+01$ & $2.90 \mathrm{E}+00$ & \\
\hline SRFA $>5 \mathrm{~K}$ red & $1.79 \mathrm{E}-02$ & $1.30 \mathrm{E}-03$ & $-1 \%$ & $2.25 \mathrm{E}-05$ & $5.31 \mathrm{E}-06$ & $76 \%$ & $2.01 \mathrm{E}+01$ & $1.93 \mathrm{E}+00$ & $-20 \%$ \\
\hline $290 \leq \lambda \leq 450 \mathrm{~nm}$ & Mean & $2 s$ & & Mean & $2 s$ & & Mean & $2 s$ & \\
\hline SRFA $<5 \mathrm{~K}$ nat & $1.99 \mathrm{E}-02$ & $2.97 \mathrm{E}-03$ & & $1.14 \mathrm{E}-05$ & $3.31 \mathrm{E}-06$ & & $2.72 \mathrm{E}+01$ & $3.11 \mathrm{E}+00$ & \\
\hline SRFA $<5 \mathrm{~K}$ red & $1.85 \mathrm{E}-02$ & $3.09 \mathrm{E}-04$ & $-7 \%$ & $2.07 \mathrm{E}-05$ & $5.40 \mathrm{E}-06$ & $81 \%$ & $2.19 \mathrm{E}+01$ & $1.53 \mathrm{E}-01$ & $-20 \%$ \\
\hline SRFA nat & $1.13 \mathrm{E}-02$ & $3.23 \mathrm{E}-04$ & & $1.10 \mathrm{E}-05$ & 4.61E-07 & & $1.61 \mathrm{E}+01$ & 8.63E-01 & \\
\hline SRFA red & $1.12 \mathrm{E}-02$ & $1.02 \mathrm{E}-04$ & $-1 \%$ & $1.38 \mathrm{E}-05$ & $2.96 \mathrm{E}-06$ & $25 \%$ & $1.72 \mathrm{E}+01$ & $3.94 \mathrm{E}-01$ & $7 \%$ \\
\hline SRFA $>5 \mathrm{~K}$ nat & $9.50 \mathrm{E}-03$ & $6.05 \mathrm{E}-04$ & & $6.78 \mathrm{E}-06$ & $2.32 \mathrm{E}-06$ & & $1.34 \mathrm{E}+01$ & $1.54 \mathrm{E}+00$ & \\
\hline SRFA $>5 \mathrm{~K}$ red & $1.06 \mathrm{E}-02$ & 7.73E-04 & $12 \%$ & $1.34 \mathrm{E}-05$ & $3.15 \mathrm{E}-06$ & $97 \%$ & $1.20 \mathrm{E}+01$ & $1.15 \mathrm{E}+00$ & $-10 \%$ \\
\hline
\end{tabular}


Table S5. Results of linear correlations between $\Phi_{1 \mathrm{O} 2}$ and E2/E3 as measured in this study. Sample acronyms are BC (Boulder Creek), BWW (Boulder Wastewater), OCWD (Orange County Wastewater), LM (Longmont Wastewater), SRFA (Suwanee River Fulvic Acid).

\begin{tabular}{|c|c|c|c|c|}
\hline Sample & Sample & Slope & Intercept & $n$ \\
\hline \multicolumn{5}{|c|}{ This study } \\
\hline $\mathrm{BC}$ & creek water & -3.57 & 23.68 & 2 \\
\hline BWW & wastewater & 1.50 & -5.13 & 2 \\
\hline OCWD & wastewater & 8.54 & -40.17 & 2 \\
\hline LM & wastewater & 1.38 & -3.97 & 5 \\
\hline SRFA native & DOM isolate & 1.61 & -5.82 & 3 \\
\hline SRFA reduced & DOM isolate & 0.95 & -4.48 & 3 \\
\hline All data besides reduced $\mathrm{S}$ & wastewater + DOM isolates & $1.59^{\mathrm{a}}$ & $-5.29^{\mathrm{a}}$ & 14 \\
\hline \multicolumn{5}{|c|}{ Previous work } \\
\hline Mostafa et al. (2013) ${ }^{1}$ & wastewater + DOM isolates & 0.72 & 0.20 & $>20$ \\
\hline Peterson et al. $(2012)^{27}$ & water from Lake Superior & 0.61 & 0.20 & $>45$ \\
\hline Dalrymple et al. $(2010)^{26}$ & DOM isolates of diverse origin & 0.87 & -1.53 & 18 \\
\hline
\end{tabular}

${ }^{\mathrm{a}}$ Significant at $\alpha=5 \%$ 

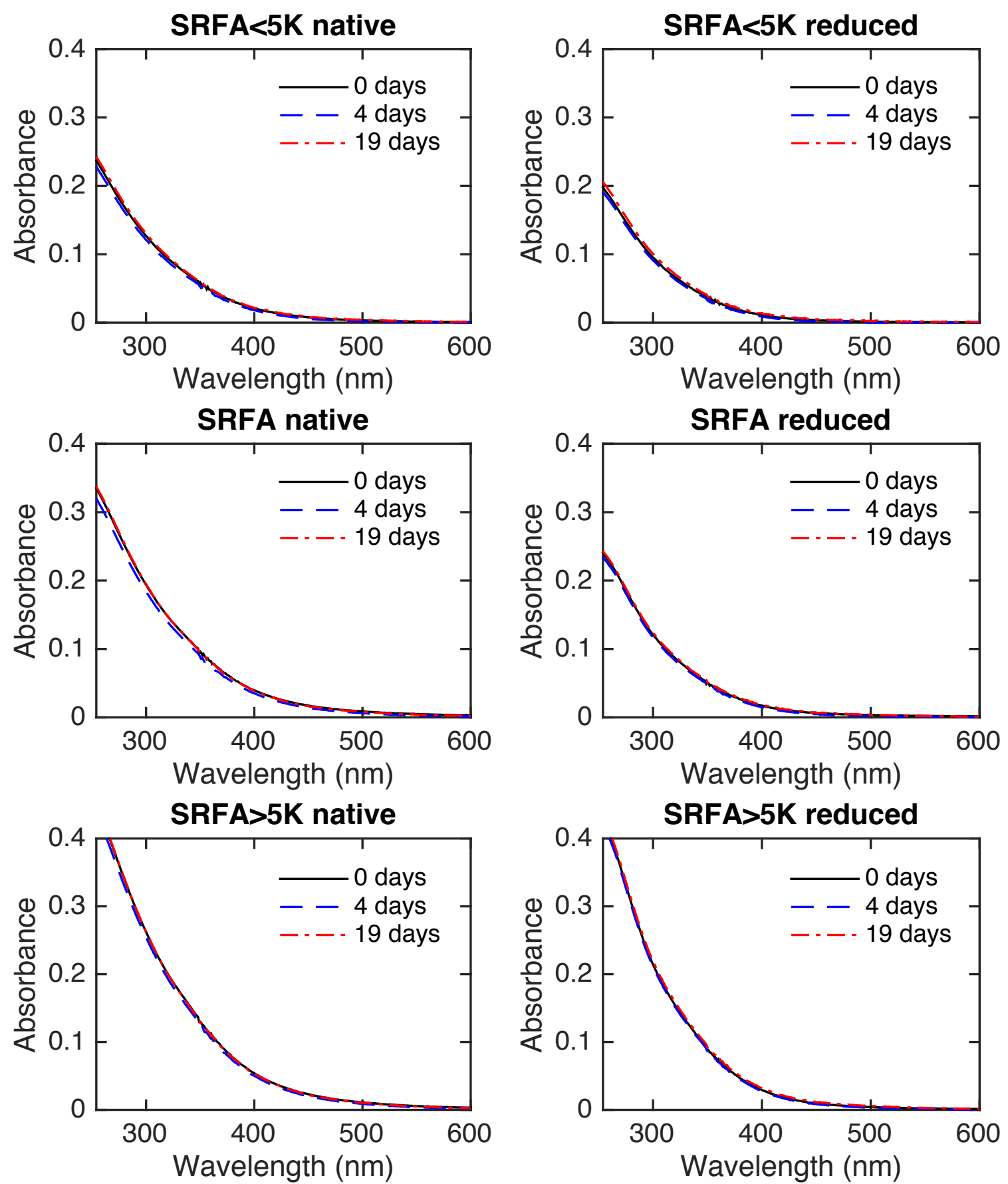

Figure S1. Time course of absorbance spectra (1 cm pathlength) for SRFA plotted from 254 to $600 \mathrm{~nm}$ for SRFA $<5 \mathrm{~K}$, unfractionated, and $>5 \mathrm{~K}$ before and after reduction with sodium borohydride over the time period of this study. 

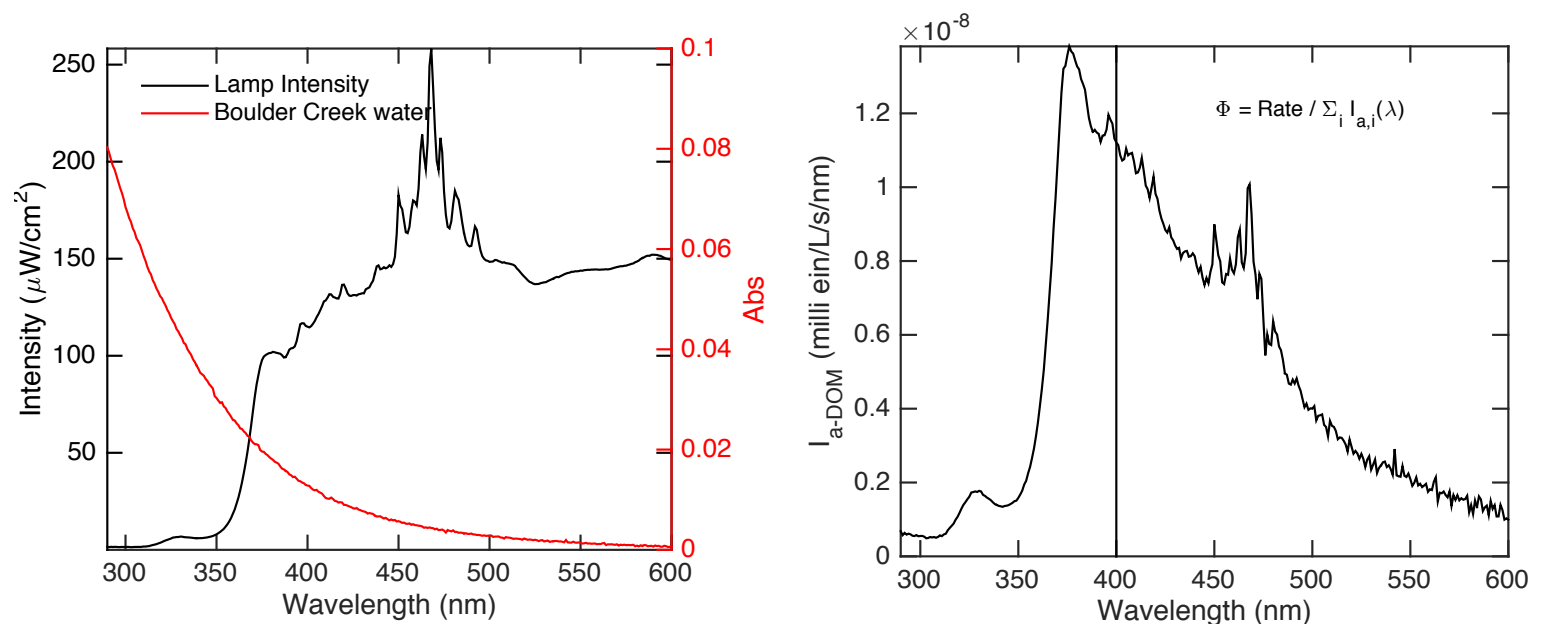

Figure S2. (Left) Lamp spectra (black, left axis) for Oriel 94041 A solar simulator described in main text and absorbance spectra (red, right axis) for Boulder Creek non-base-modified. (Right) calculation of the rate of light absorption by DOM based on eq. S 2). 

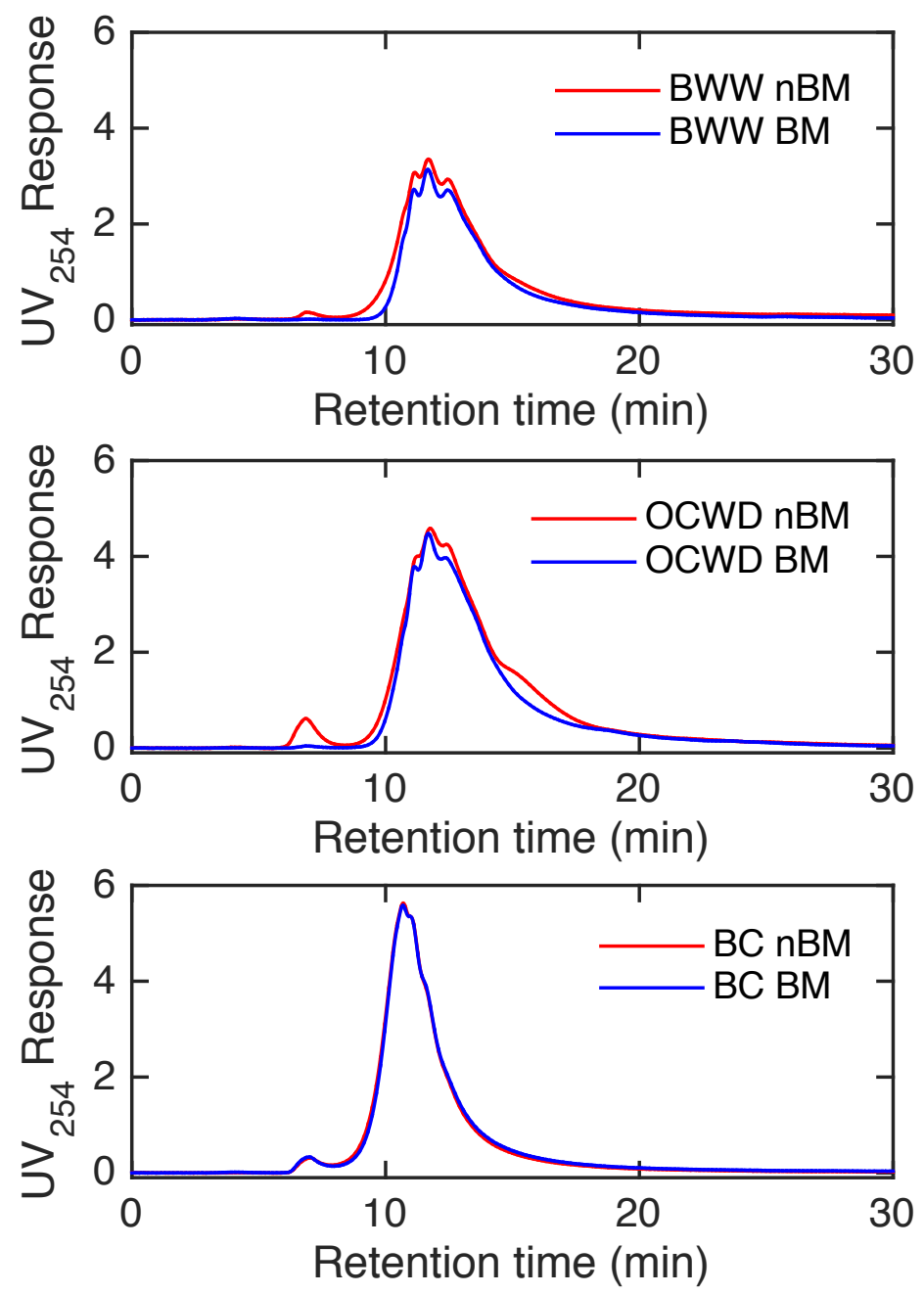

Figure S3. Size exclusion chromatograms for pre-and post-base-modified samples. Solution and eluent conditions are given in ref. ${ }^{28}$ Detector was a VWD set at $254 \mathrm{~nm}$. 

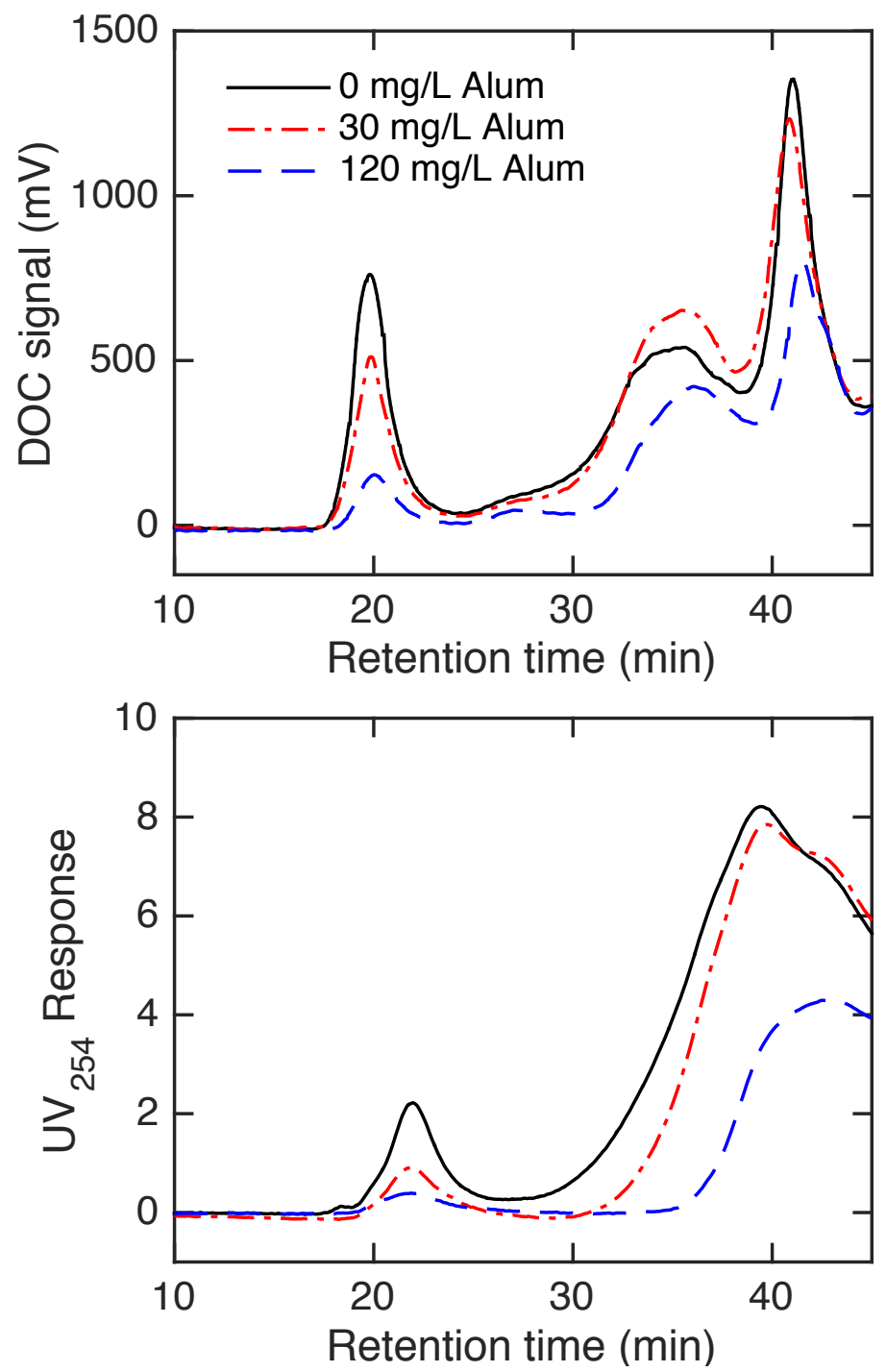

Figure S4. Size exclusion chromatograms for LM wastewater pre- and post-coagulation with alum. Note that DOC signal in top plot has been baseline subtracted (actual baseline was around $800 \mathrm{mV}$ ). Solution and eluent conditions are given in ref. ${ }^{28}$ 

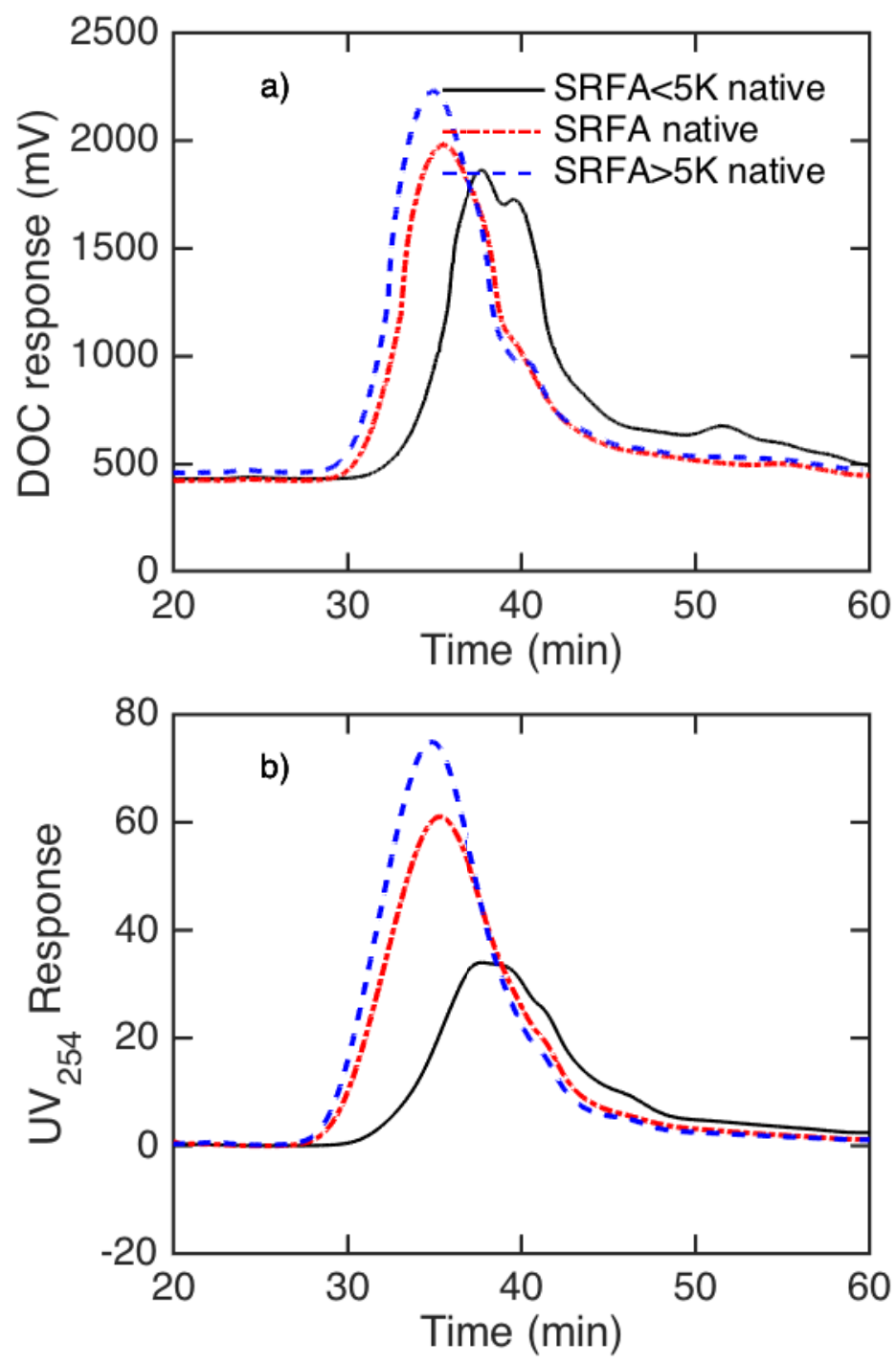

Figure S5. Size exclusion chromatograms for for SRFA $<5 \mathrm{~K}$, unfractionated, and $>5 \mathrm{~K}$ before reduction with sodium borohydride. a) DOC response and b) UV response at $254 \mathrm{~nm}$. Solution and eluent conditions are given in ref. ${ }^{28}$ 

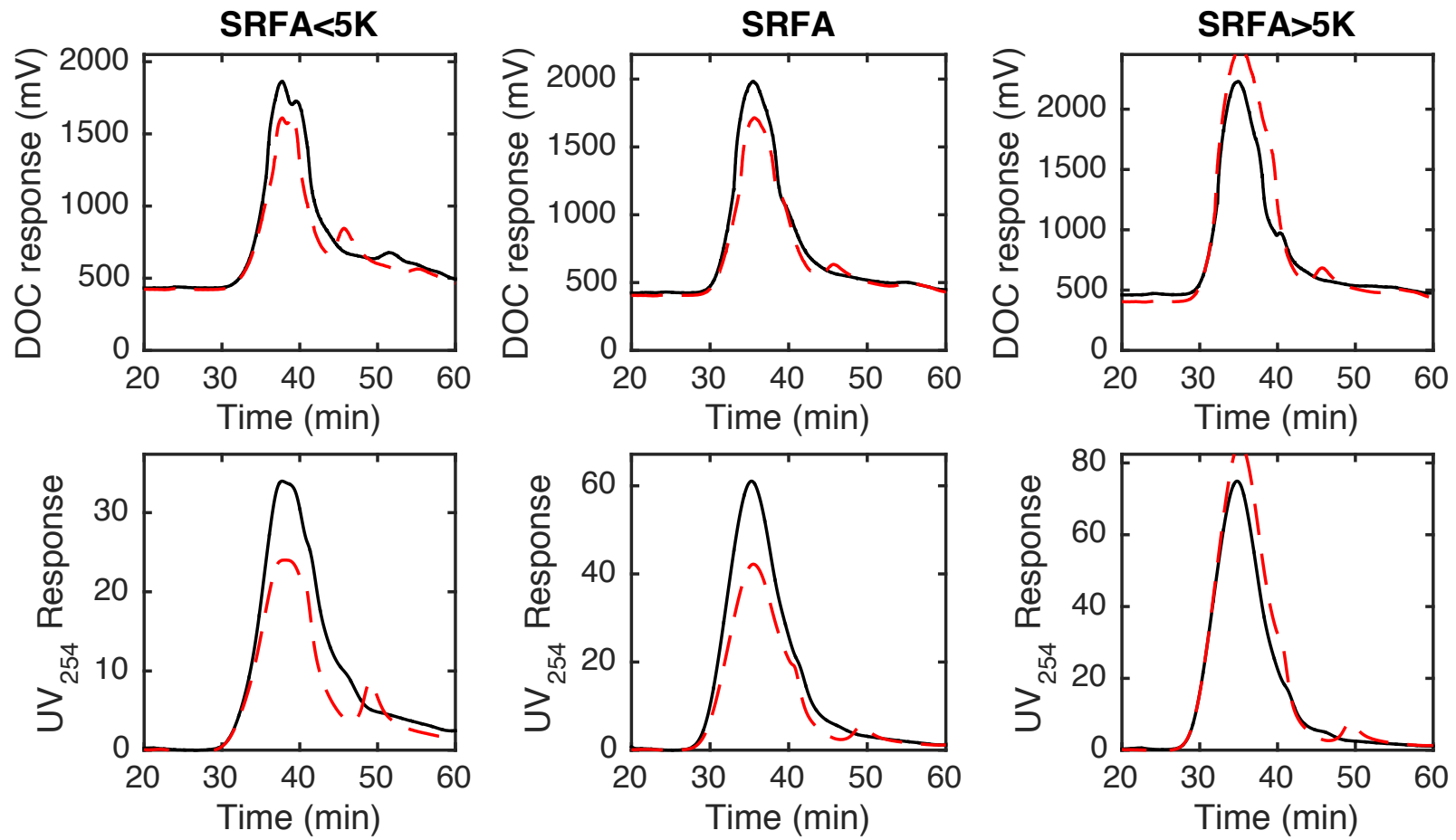

Figure S6. Size exclusion chromatograms for SRFA $<5 \mathrm{~K}$, unfractionated, and $>5 \mathrm{~K}$ before (solid, black line) and after reduction (dashed, red line) with sodium borohydride. Solution and eluent conditions are given in ref. ${ }^{28}$ 

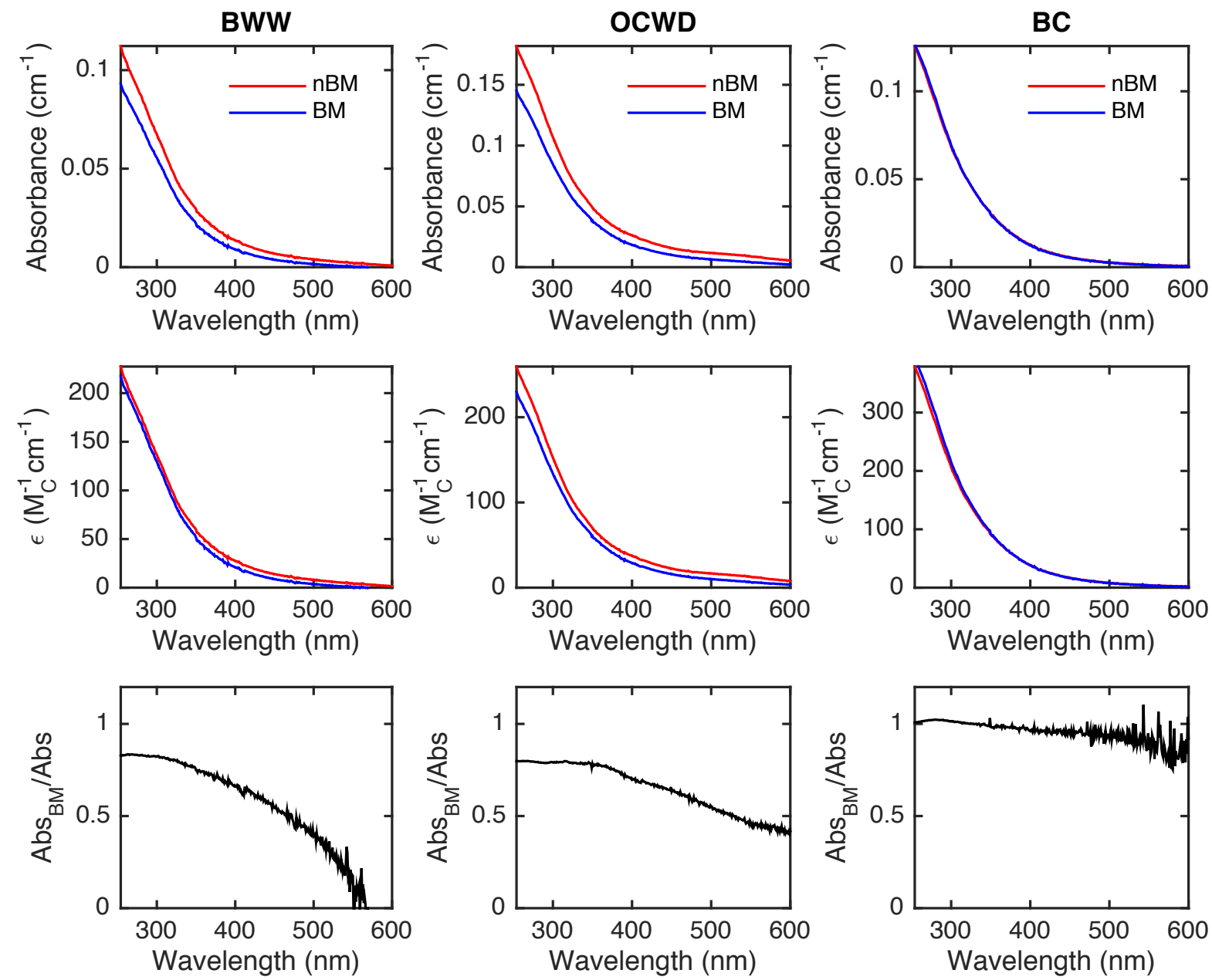

Figure S7. (First row) Absorbance spectra (1 cm pathlength) plotted from 254 to $600 \mathrm{~nm}$ for BWW, OCWD, and BC. (Second row) Molar absorptivity on a per-carbon basis based on data in first row and TOC values in Table S1. (Third row) Fractional absorbance based on data in first row. $\mathrm{nBM}$ and $\mathrm{BM}$ refer to non-base-modified and base modified, respectively. 

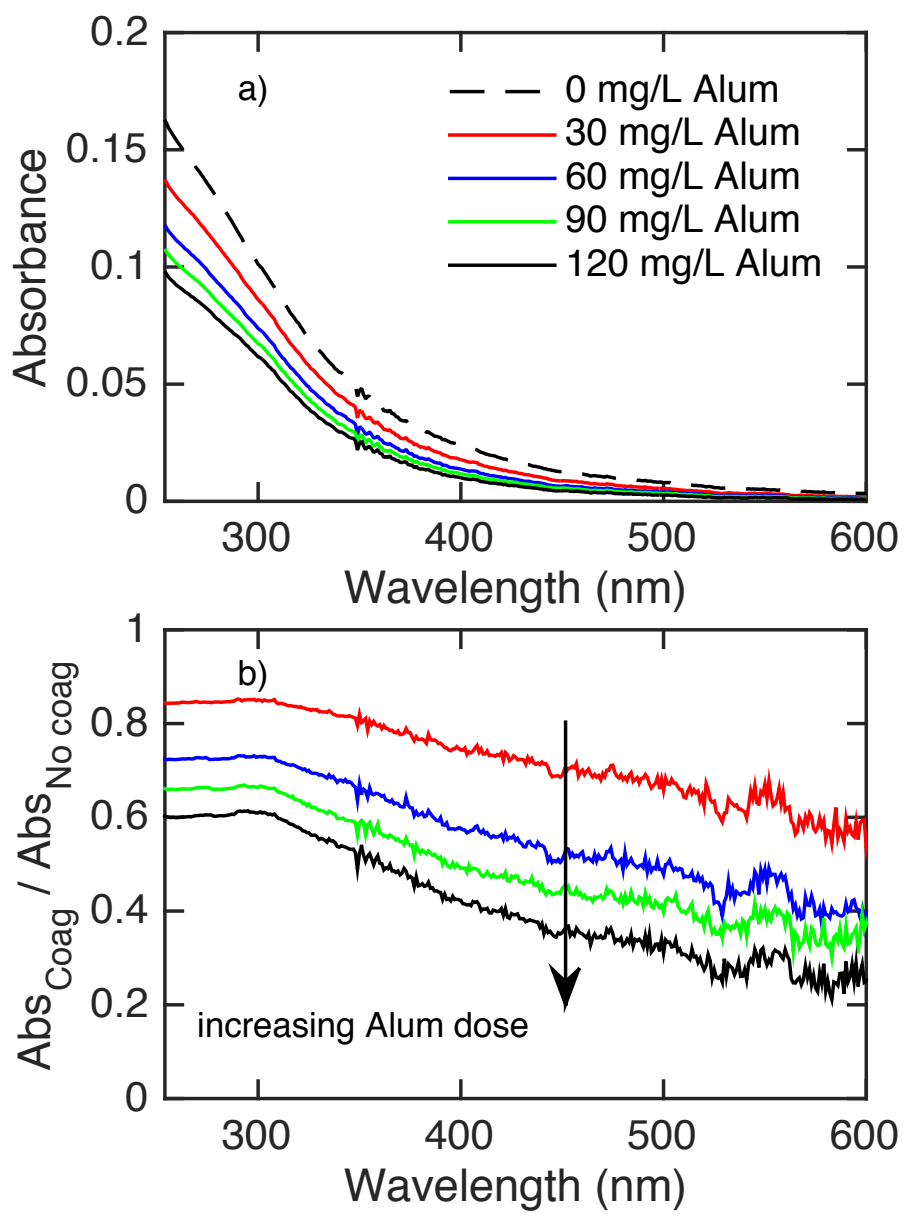

Figure S8. Absorption spectra (1 cm pathlength) for LM wastewater plotted from 254 to $600 \mathrm{~nm}$ and fractional absorbance based on data in a). 


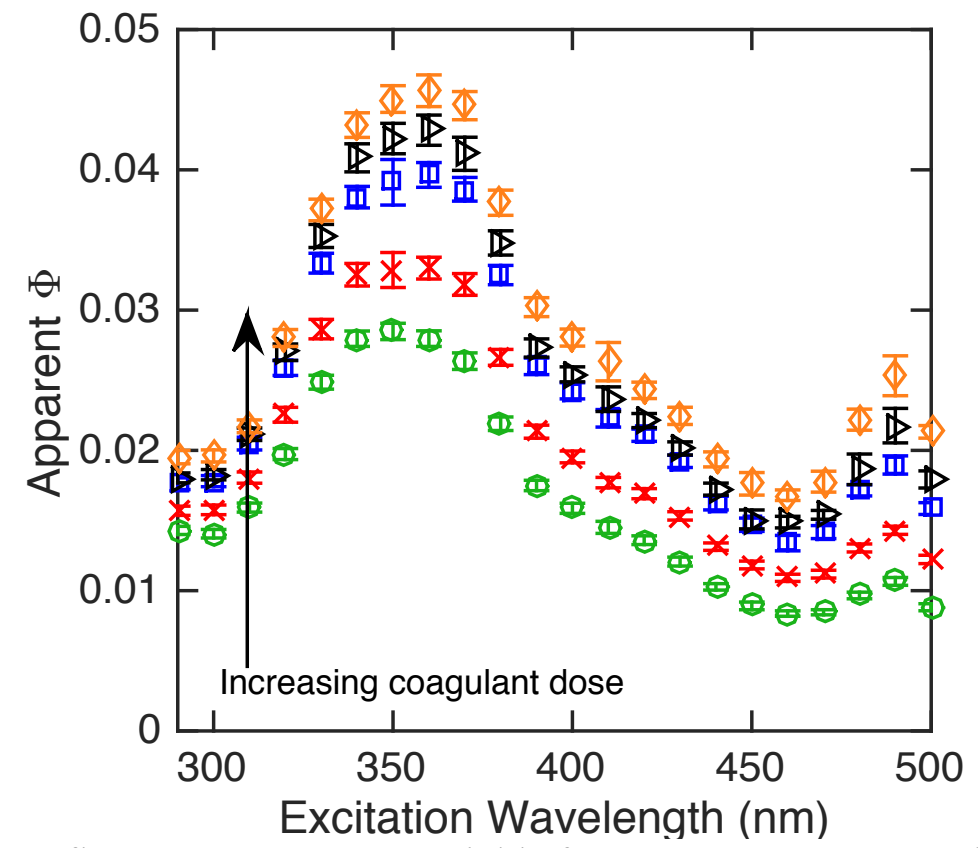

Figure S9. Apparent fluorescence quantum yields for LM wastewater as a function of increasing alum dose. 

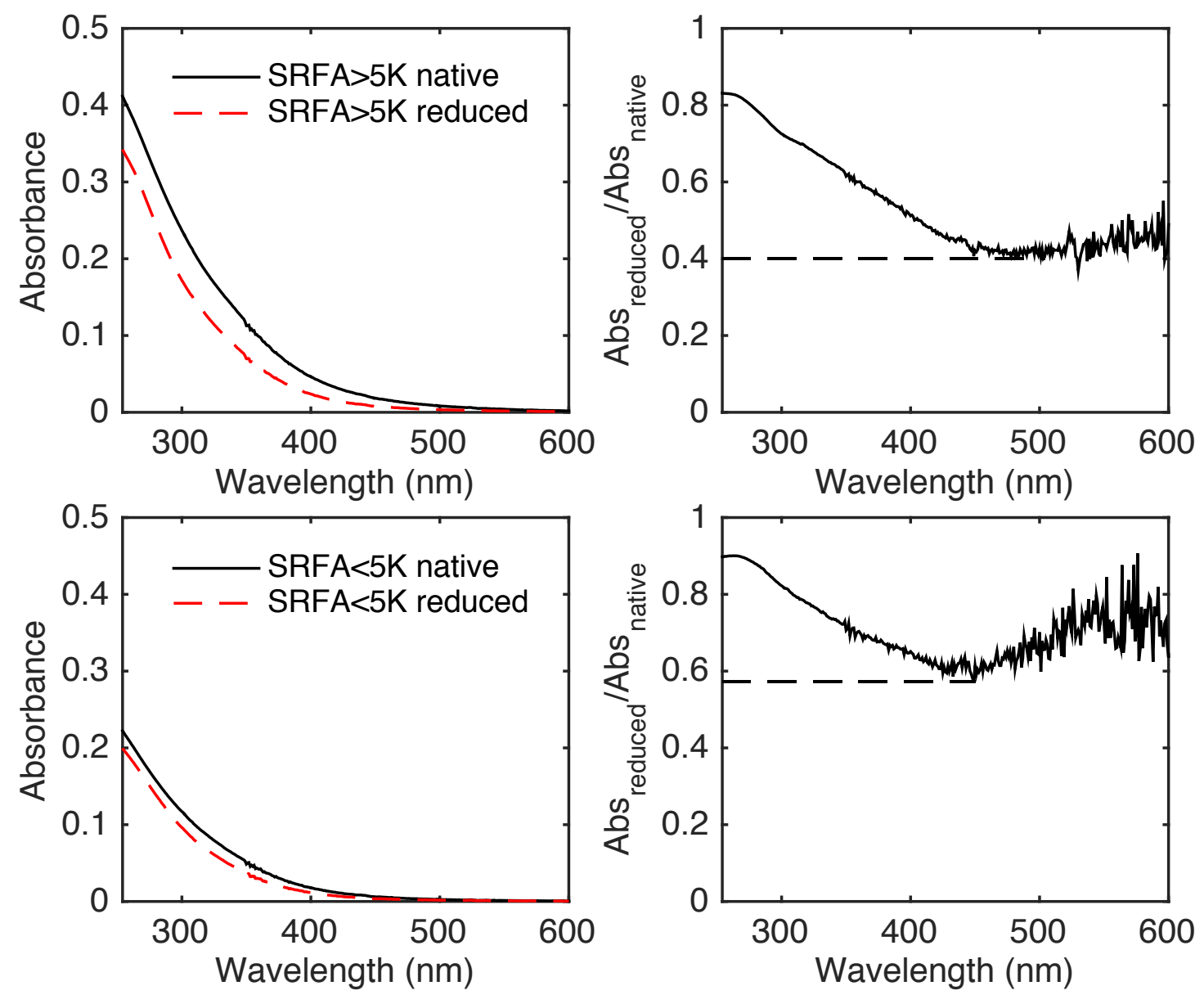

Figure S10. Absorption spectra (1 cm pathlength) plotted from 254 to $600 \mathrm{~nm}$ for SRFA $>5 \mathrm{~K}$ and SRFA $<5 \mathrm{~K}$ fractions pre- and post-reduction. $f_{\mathrm{a}, \text { min }}$ values for SRFA $>5 \mathrm{~K}$ and SRFA $<5 \mathrm{~K}$ are 0.401 and 0.573 , respectively. 

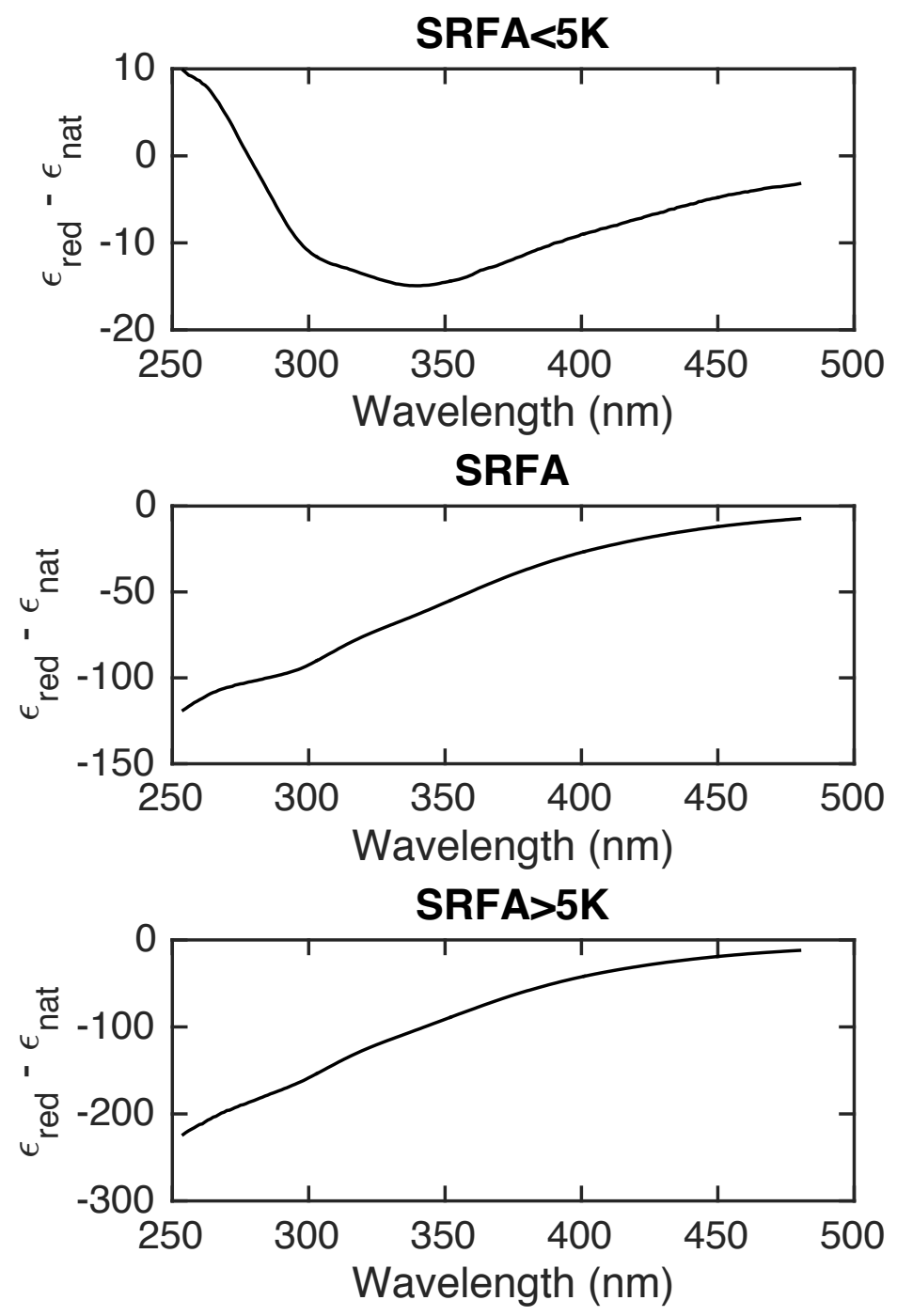

Figure S11. Plot of $\varepsilon_{\text {red }}-\varepsilon_{\text {nat }}$ for SRFA molecular weight fractions. Integration of the area between the curve and $\varepsilon_{\text {red }}-\varepsilon_{\text {nat }}=0$ gives the area for the metric provided in Table S3 (row 3 ). 

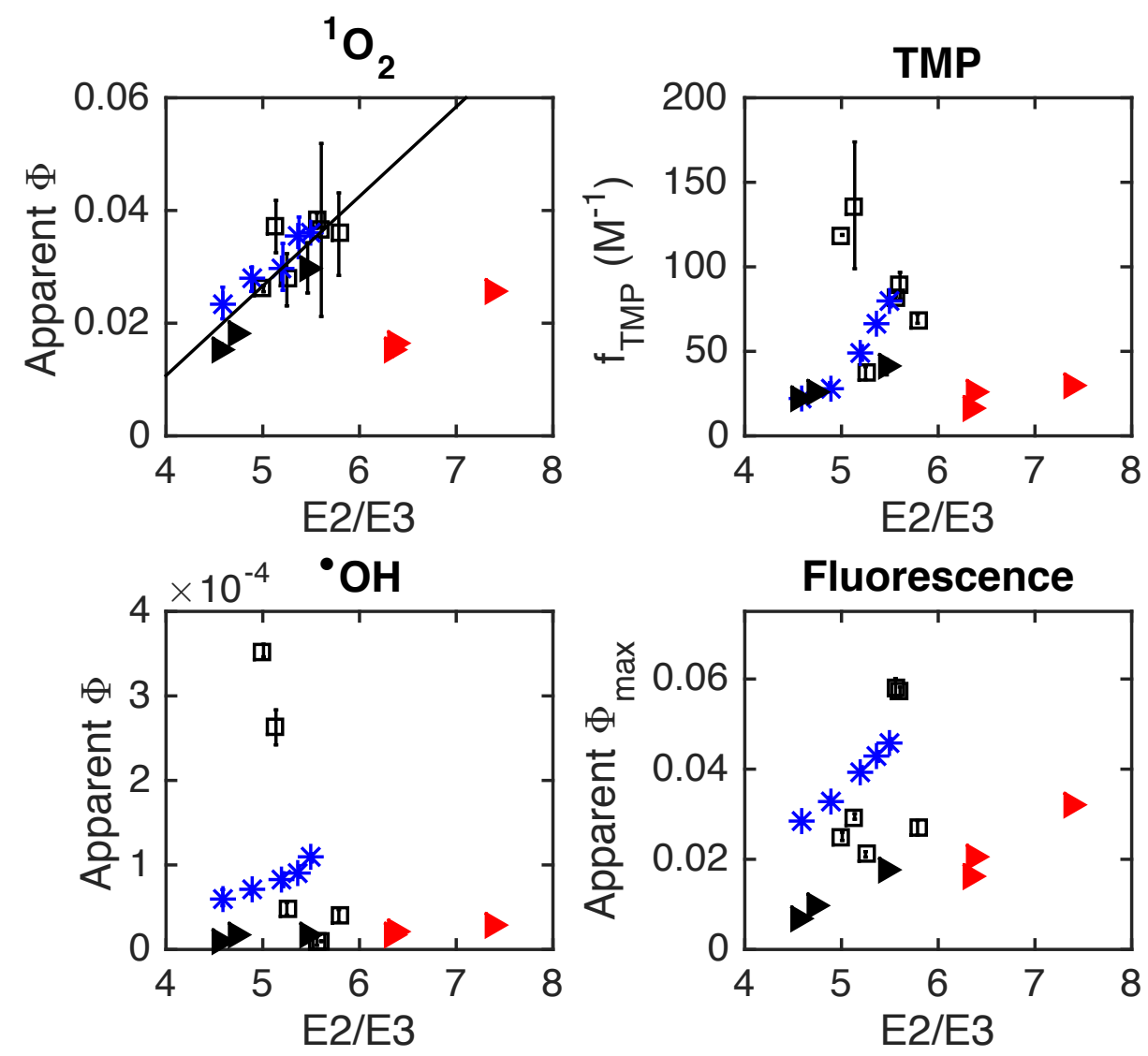

․ base-modified * LM coagulated

$\rightarrow$ SRFA native $>$ SRFA reduced

Figure S12. Plots of apparent $\Phi$ versus E2/E3 for all samples in this study. See legend for sample identity. Solid line for ${ }^{1} \mathrm{O}_{2}$ represents linear regression of $\Phi_{102}$ and E2/E3 excluding SRFA reduced samples. Regression relation is $\Phi_{102}(\%)=1.59 \times \mathrm{E} 2 / \mathrm{E} 3-5.29$. Both the slope $(p<$ $0.0001)$ and intercept $(p<0.01)$ are significant. 

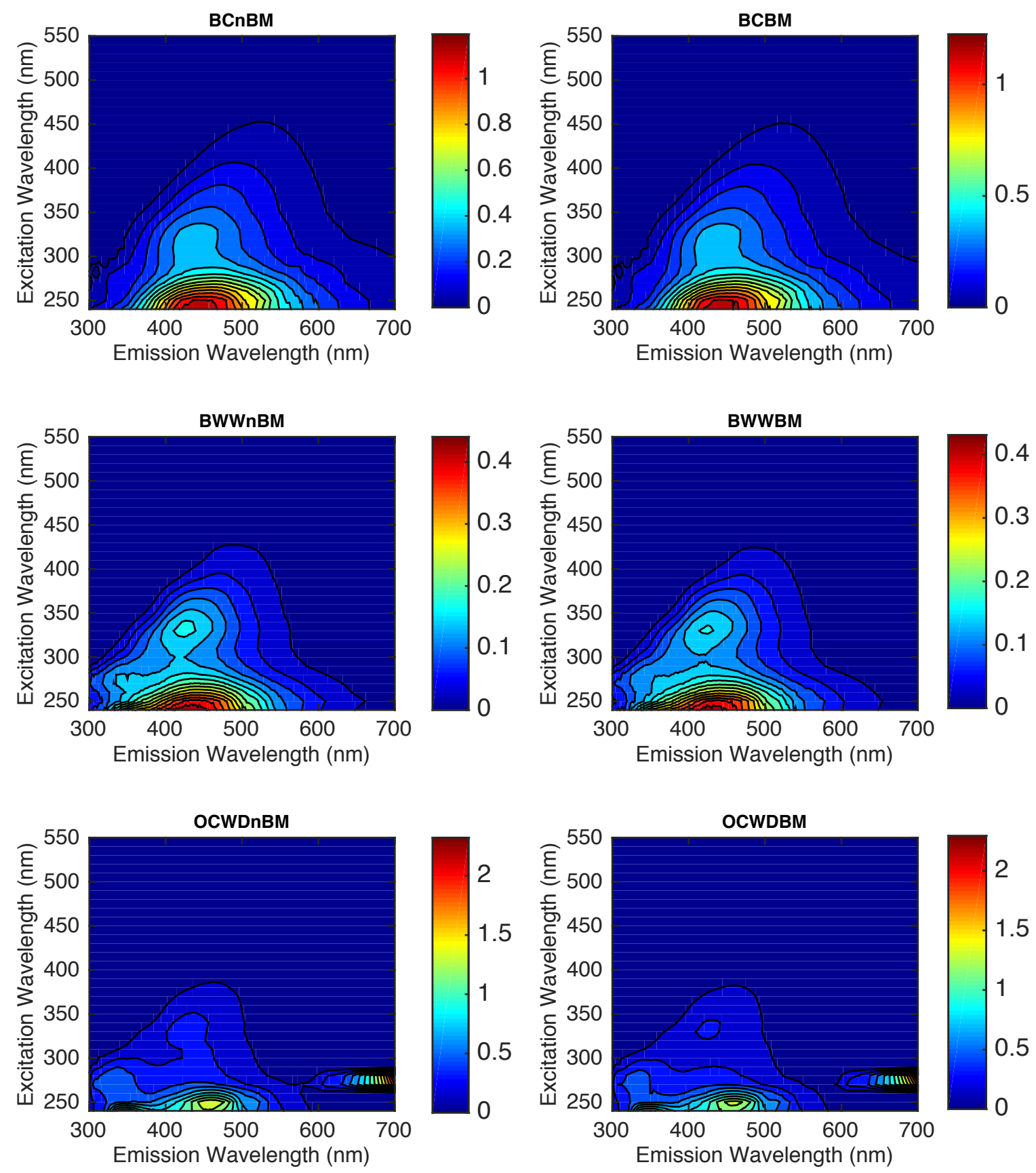

Figure S13. Three dimensional excitation emission matrices for BC, BWW, and OCWD pre- and post-base-modification. 

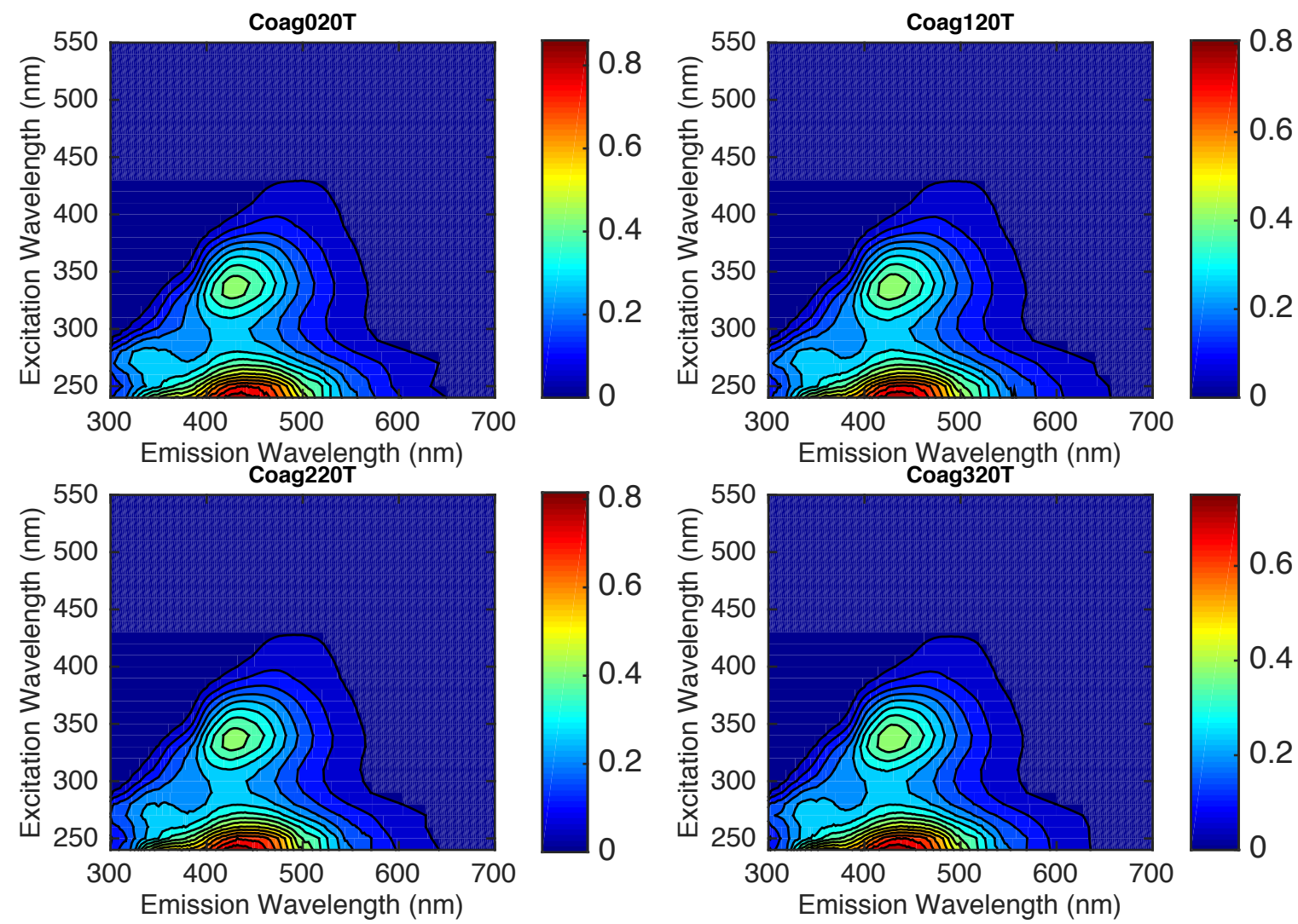

Figure S14. Three dimensional excitation emission matrices for LM as a function of coagulation dose. From top left: Coag0 $=0 \mathrm{mg}$ alum $/ \mathrm{L}$, Coag $1=30 \mathrm{mg}$ alum $/ \mathrm{L}$, Coag2 $=60 \mathrm{mg}$ alum $/ \mathrm{L}$, Coag $3=90 \mathrm{mg}$ alum $/ \mathrm{L}$. 

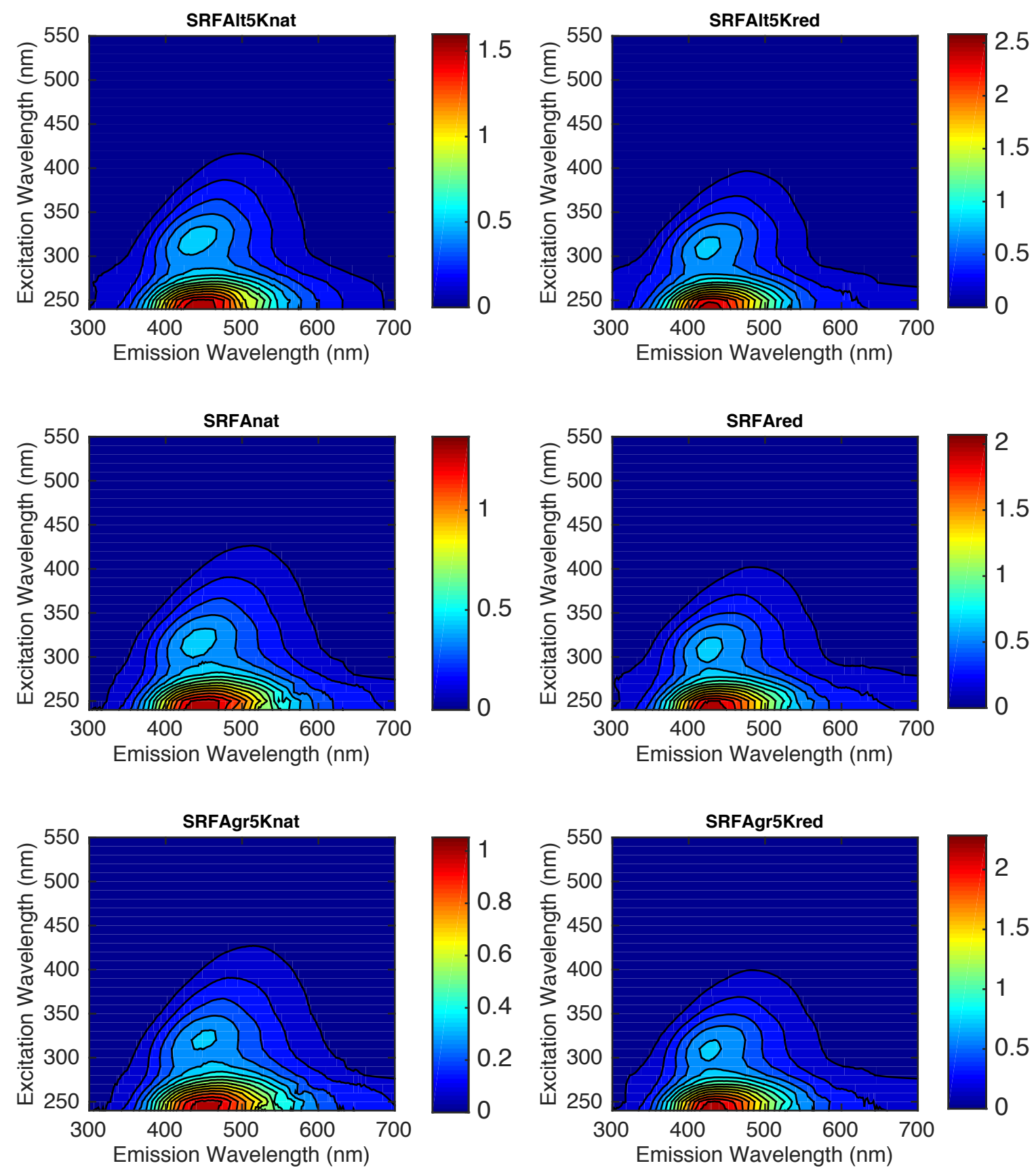

Figure S15. Three dimensional excitation emission matrices for SRFA before and after reduction with sodium borohydride. 


\section{References}

(1) Mostafa, S.; Rosario-Ortiz, F. L. Singlet oxygen formation from wastewater organic matter. Environmental Science \& Technology 2013, 47 (15), 8179-8186.

(2) Bodhipaksha, L. C.; Sharpless, C. M.; Chin, Y.-P.; Sander, M.; Langston, W. K.; MacKay, A. A. Triplet Photochemistry of Effluent and Natural Organic Matter in Whole Water and Isolates from Effluent-Receiving Rivers. Environmental Science \& Technology 2015, 49 (6), 3453-3463.

(3) McKay, G.; Rosario-Ortiz, F. L. Temperature Dependence of the Photochemical Formation of Hydroxyl Radical from Dissolved Organic Matter. Environmental Science \& Technology 2015, 49 (7), 4147-4154.

(4) Dong, M. M.; Rosario-Ortiz, F. L. Photochemical Formation of Hydroxyl Radical from Effluent Organic Matter. Environmental Science \& Technology 2012, 46 (7), 37883794.

(5) Leifer, A. The kinetics of environmental aquatic photochemistry: theory and practice; American Chemical Society, 1988.

(6) Birks, J. B. Photophysics of aromatic molecules; John Wiley \& Sons Ltd, 1970.

(7) Mulliken, R. S. Molecular compounds and their spectra. II. J. Am. Chem. Soc. 1952, 74 (3), 811-824.

(8) Aiken, G. R.; Malcolm, R. L. Molecular weight of aquatic fulvic acids by vapor pressure osmometry. Geochimica et Cosmochimica Acta 1987, 51, 2177-2184.

(9) humicsubstances.org.

(10) Thurman, E. M.; Malcolm, R. L. Structural study of humic substances: new approaches and methods. Aquatic and terrestrial humic materials 1983, 1-23.

(11) Sharpless, C. M.; Blough, N. V. The importance of charge-transfer interactions in determining chromophoric dissolved organic matter (CDOM) optical and photochemical properties. Environ. Sci.: Processes Impacts 2014, 16 (4), 654.

(12) Aeschbacher, M.; Sander, M.; Schwarzenbach, R. P. Novel electrochemical approach to assess the redox properties of humic substances. Environmental Science \& Technology 2010, 44 (1), 87-93.

(13) Wenk, J.; Gunten, von, U.; Canonica, S. Effect of Dissolved Organic Matter on the Transformation of Contaminants Induced by Excited Triplet States and the Hydroxyl Radical. Environmental Science \& Technology 2011, 45 (4), 1334-1340.

(14) IHSS - Elemental Compositions and Stable Isotopic Ratios of IHSS Samples. humicsubstances.org.

(15) Latch, D. E. Microheterogeneity of Singlet Oxygen Distributions in Irradiated Humic Acid Solutions. Science 2006, 311 (5768), 1743-1747.

(16) Lee, E.; Glover, C. M.; Rosario-Ortiz, F. L. Photochemical Formation of Hydroxyl Radical from Effluent Organic Matter: Role of Composition. Environmental Science \& Technology 2013, 47 (21), 12073-12080.

(17) Mostafa, S.; Korak, J. A.; Shimabuku, K.; Glover, C. M.; Rosario-Ortiz, F. L. Relation between Optical Properties and Formation of Reactive Intermediates from Different Size Fractions of Organic Matter. In ACS Symposium Series; ACS Symposium Series; American Chemical Society: Washington, DC, 2014; Vol. 1160, pp 159-179.

(18) Gan, D.; Jia, M.; Vaughan, P. P.; Falvey, D. E.; Blough, N. V. Aqueous Photochemistry of Methyl-Benzoquinone. J. Phys. Chem. A 2008, 112 (13), 2803-2812. 
(19) Tinnacher, R. M.; Honeyman, B. D. A New Method to Radiolabel Natural Organic Matter by Chemical Reduction with Tritiated Sodium Borohydride. Environmental Science \& Technology 2007, 41 (19), 6776-6782.

(20) Sharpless, C. M. Lifetimes of Triplet Dissolved Natural Organic Matter (DOM) and the Effect of NaBH 4Reduction on Singlet Oxygen Quantum Yields: Implications for DOM Photophysics. Environmental Science \& Technology 2012, 46 (8), 4466-4473.

(21) Vaughan, P. P.; Blough, N. V. Photochemical formation of hydroxyl radical by constituents of natural waters. Environmental Science \& Technology 1998, 32 (19), 2947-2953.

(22) White, E.; Vaughan, P.; Zepp, R. Role of the photo-Fenton reaction in the production of hydroxyl radicals and photobleaching of colored dissolved organic matter in a coastal river of the southeastern United States. Aquat Sci 2003, 65 (4), 402-414.

(23) Grannas, A. M.; Martin, C. B.; Chin, Y.-P.; Platz, M. Hydroxyl Radical Production from Irradiated Arctic Dissolved Organic Matter. Biogeochemistry 2006, 78 (1), 51-66.

(24) Glover, C. M.; Rosario-Ortiz, F. L. Impact of Halides on the Photoproduction of Reactive Intermediates from Organic Matter. Environmental Science \& Technology 2013, 47 (24), 13949-13956.

(25) Golanoski, K. S.; Fang, S.; Del Vecchio, R.; Blough, N. V. Investigating the Mechanism of Phenol Photooxidation by Humic Substances. Environmental Science \& Technology 2012, 46 (7), 3912-3920.

(26) Dalrymple, R. M.; Carfagno, A. K.; Sharpless, C. M. Correlations between Dissolved Organic Matter Optical Properties and Quantum Yields of Singlet Oxygen and Hydrogen Peroxide. Environmental Science \& Technology 2010, 44 (15), 5824-5829.

(27) Peterson, B. M.; McNally, A. M.; Cory, R. M.; Thoemke, J. D.; Cotner, J. B.; McNeill, K. Spatial and Temporal Distribution of Singlet Oxygen in Lake Superior. Environmental Science \& Technology 2012, 46 (13), 7222-7229.

(28) Dong, M. M.; Mezyk, S. P.; Rosario-Ortiz, F. L. Reactivity of effluent organic matter (EfOM) with hydroxyl radical as a function of molecular weight. Environmental Science \& Technology 2010, 44 (15), 5714-5720. 